\title{
Different Influences of Southeastern Indian Ocean and Western Indian Ocean SST Anomalies on Eastern China Rainfall during the Decaying Summer of the 2015/16 Extreme EI Niño
}

\author{
JIEPENG CHEN \\ State Key Laboratory of Tropical Oceanography, South China Sea Institute of Oceanology, Chinese Academy of Sciences, \\ Guangzhou, and State Key Laboratory of Satellite Ocean Environment Dynamics, Second Institute of Oceanography, \\ Ministry of Natural Resources, Hangzhou, and Southern Marine Science and Engineering Guangdong Laboratory \\ (Guangzhou), and Innovation Academy of South China Sea Ecology and Environmental Engineering, Chinese Academy \\ of Sciences, Guangzhou, China, and Department of Earth System Science, University of California, Irvine, California \\ JIN-YI YU \\ Department of Earth System Science, University of California, Irvine, California \\ XIN WANG \\ State Key Laboratory of Tropical Oceanography, South China Sea Institute of Oceanology, and Southern Marine Science and \\ Engineering Guangdong Laboratory (Guangzhou), and Innovation Academy of South China Sea Ecology and \\ Environmental Engineering, Chinese Academy of Sciences, Guangzhou, China
}

TAO LIAN

State Key Laboratory of Satellite Ocean Environment Dynamics, Second Institute of Oceanography, Ministry of Natural Resources, Hangzhou, China

(Manuscript received 16 October 2019, in final form 31 March 2020)

\begin{abstract}
Previous studies linked the increase of the middle and low reaches of the Yangtze River (MLRYR) rainfall to tropical Indian Ocean warming during extreme El Niños' (e.g., 1982/83 and 1997/98 extreme El Niños) decaying summer. This study finds the linkage to be different for the recent 2015/16 extreme El Niño's decaying summer, during which the above-normal rainfalls over MLRYR and northern China are respectively linked to southeastern Indian Ocean warming and western tropical Indian Ocean cooling in sea surface temperatures (SSTs). The southeastern Indian Ocean warming helps to maintain the El Niño-induced anomalous lower-level anticyclone over the western North Pacific Ocean and southern China, which enhances moisture transport to increase rainfall over MLRYR. The western tropical Indian Ocean cooling first enhances the rainfall over central-northern India through a regional atmospheric circulation, the latent heating of which further excites a midlatitude Asian teleconnection pattern (part of circumglobal teleconnection) that results in an above-normal rainfall over northern China. The western tropical Indian Ocean cooling during the 2015/16 extreme El Niño is contributed by the increased upward latent heat flux anomalies associated with enhanced surface wind speeds, opposite to the earlier two extreme El Niños.
\end{abstract}

\section{Introduction}

Eastern China is located within the East Asian monsoon region. Its summer rainfall accounts for the largest fraction of the annual rainfall (Wu et al. 2003). Abnormal increases of summer rainfall can result in

\footnotetext{
Corresponding author: Xin Wang, wangxin@scsio.ac.cn
}

severe floods in the region (e.g., 1983, 1991, 1998, 2016) and cause huge social and economic damage. Intensive efforts have been made to better understand and predict the summer rainfall variability over eastern China (e.g., Lau and Weng 2001; Li et al. 2017; Yuan et al. 2017; Gao et al. 2018). El Niño-Southern Oscillation (ENSO) is one of the most important factors for modulating the interannual variability of eastern China summer rainfall 
(e.g., Huang and Wu 1989; Zhang et al. 1999; Lau and Weng 2001; Wu et al. 2003; Wang et al. 2009; Wu et al. 2009; Han et al. 2017; Zhang et al. 2017). An empirical orthogonal function (EOF) study (Wu et al. 2009) showed the first two dominant modes of precipitation variability over East Asia correspond respectively to the ENSO decaying and turnabout years. How the ENSO impacts the spatial-temporal patterns of rainfall over eastern China was revealed by Wu et al. (2003) in a laglead correlation/regression study. They noticed the winter Niño-3.4 SST has significant negative correlations with rainfall over northern China during the ENSO developing year and significant positive correlations with the middle reaches of the Yangtze River during the ENSO decaying year. The correlation is weak between the northern China rainfall and the preceding winter Niño-3.4 SST.

In recent years, a new type of El Niño, with maximum warm SST anomalies in the equatorial central Pacific Ocean and cold SST anomalies in the equatorial western and eastern Pacific, has been widely investigated (Ashok et al. 2007; Kao and Yu 2009; Kug et al. 2009; Yu and Kim 2010, 2011; Yu et al. 2010, 2012, 2015; Wang and Wang 2013). In this study, conventional ENSO and the new type of ENSO are respectively referred to as eastern Pacific (EP) ENSO and central Pacific (CP) ENSO, following Kao and $\mathrm{Yu}$ (2009). The two types of ENSO have remarkable different impacts on eastern China rainfall anomalies, which are mainly attributed to the different evolutions and locations of the anomalous lower-level western North Pacific anticyclone they induce (Weng et al. 2007, 2009; Feng et al. 2011; Yuan and Yang 2012). During the decaying summer of the EP El Niño, positive rainfall anomalies occur over the middle and lower reaches of the Yangtze River (MLRYR) and negative rainfall anomalies occur from north of the Yangtze River to the Yellow River. In contrast, the anomalous rainfall distribution tends to be of opposite sign during the decaying summer of the CP El Niño. This is because the anomalous western North Pacific anticyclone extends more northwestward during the CP El Niño than during the EP El Niño (Feng et al. 2011). The Indian Ocean also plays some roles in modulating the anomalous anticyclone. A tropical Indian Ocean warming occurs and contributes to the persistence of the western North Pacific anticyclone via a Kelvin waveEkman divergence mechanism (Xie et al. 2009) during the decaying summer of EP El Niño, whereas the tropical Indian Ocean SSTs seem to exert a negligible impact on the western North Pacific anticyclone when tropical Indian Ocean warming mode disappears in the decaying summer of the CP El Niño (Feng et al. 2011; Yuan et al. 2012; Chen et al. 2019; Paek et al. 2019).
Since the 1990s, not only does the occurrence frequency of CP El Niño increase (Ashok et al. 2007; Kug et al. 2009; Yeh et al. 2009; Yu et al. 2012; Freund et al. 2019), but also its intensity strengthens (Lee and McPhaden 2010). The latest 2015/16 extreme El Niño has characteristics of both the CP and EP El Niños (Paek et al. 2017), while the earlier two extreme El Niños (1982/83 and 1997/98) are considered as pure EP type (Feng et al. 2011; Wang and Wang 2013; Paek et al. 2017). The 2015/16 El Niño peaked in winter and had a comparable intensity of equatorial eastern Pacific SST anomalies as the earlier two extreme El Niños. All three had peak intensities reaching two standard deviations in the Niño-3.4 and Niño-3 indices (J. P. Chen et al. 2018). However, SST anomalies over the Niño- $1+2$ region is $1^{\circ} \mathrm{C}$ smaller during the $2015 / 16 \mathrm{El}$ Niño than during the other two extreme El Niños. Besides, during the 2015/16 event, SST anomalies over the Niño-4 region reached a record value of $1.7^{\circ} \mathrm{C}$, which is $1^{\circ} \mathrm{C}\left(0.8^{\circ} \mathrm{C}\right)$ larger than that of the 1982/83 (1997/98) event. Correspondingly, enhanced convection shifted westward by $20^{\circ}$ in longitude (Xue and Kumar 2017). In the decaying phase, warm SST anomalies decayed westward from the South American coast during the 2015/16 El Niño, while warm SST anomalies retracted back to the South American coast during the two earlier extreme El Niños (L'Heureux et al. 2017; Paek et al. 2017). These different evolution features imply that the climate impact of the 2015/16 El Niño may be different from that of a pure EP El Niño.

The EP El Niño can induce an Indian Ocean basin warming, which typically persists from the developing to decaying summers and plays a vital role in influencing the summer lower-level western North Pacific anticyclone. The disturbed anticyclone can then affect rainfall variability over MLRYR. Han et al. (2017, 2018) indicated the spring tropical Indian Ocean SST anomalies exert a considerable influence on summer rainfall anomalies over northeastern China. During the decaying summer of the 2015/16 extreme El Niño, the eastern China rainfall pattern is characterized by two positive anomaly centers separately located over MLRYR and northern China (Fig. 1a). A western North Pacific anticyclonic anomaly maintained through July 2016 and favored above-normal summer rainfall over MLRYR as expected (Yuan et al. 2017; Li et al. 2017). However, in contrary to the expectation, warm Indian Ocean SST anomalies were confined in the southeastern Indian Ocean while cold SST anomalies appeared in the western tropical Indian Ocean (J. P. Chen et al. 2018; Z. S. Chen et al. 2018; Liu et al. 2018). In addition, the positive rainfall anomalies over northern China deviated from the typical negative correlation between winter Niño-3 SST and following 

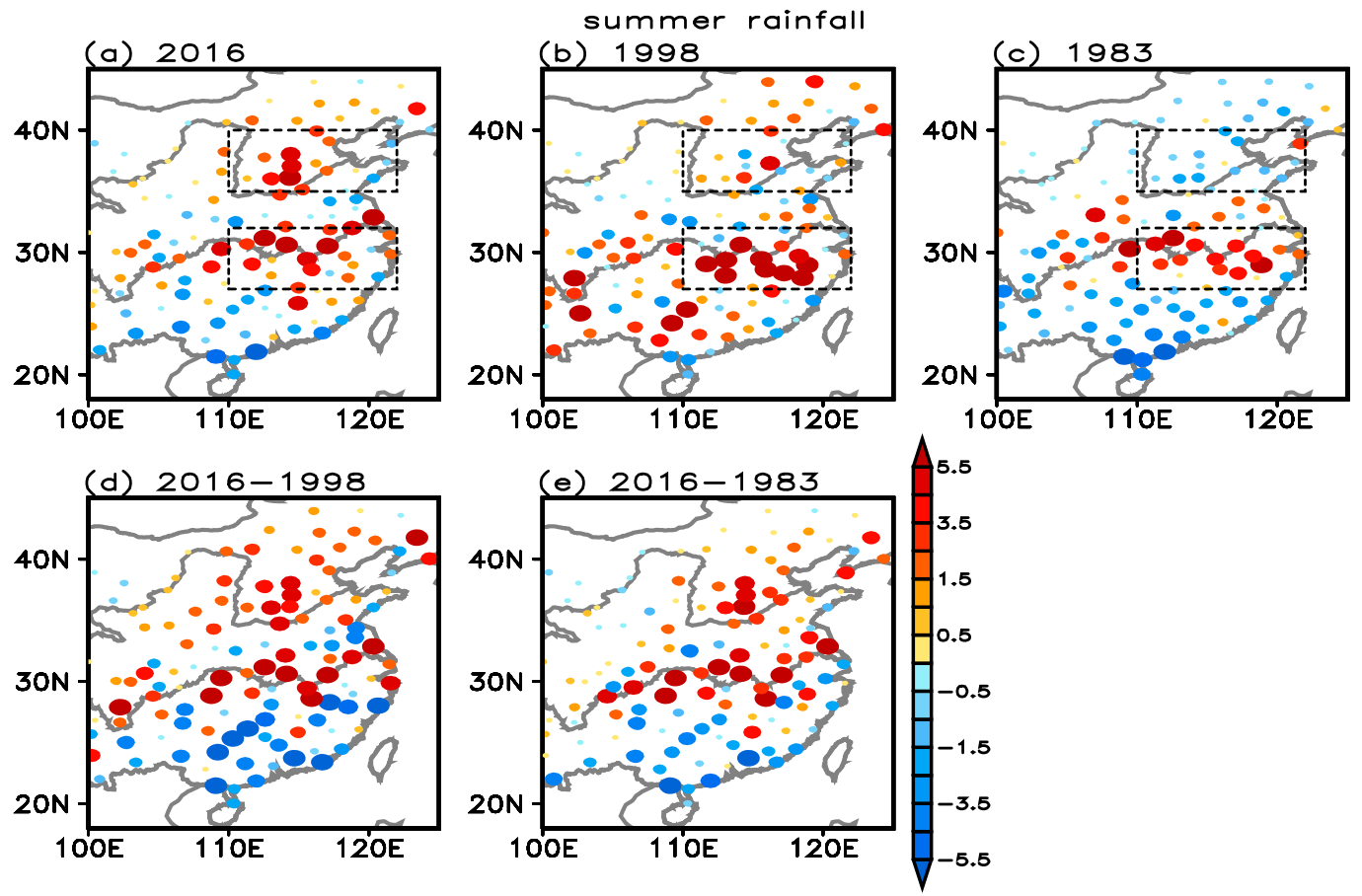

FIG. 1. Rainfall anomalies (mm day ${ }^{-1}$ ) in the summer (June and July mean) of (a) 2016, (b) 1998, and (c) 1983. Also shown is the difference of the rainfall in the summer of 2016 minus the rainfall in the summer of (d) 1998 and (e) 1983, respectively. The southern and northern dashed rectangles represent the regions of middle and low reaches of the Yangtze River (MLRYR; $\left.110^{\circ}-122^{\circ} \mathrm{E}, 27^{\circ}-32^{\circ} \mathrm{N}\right)$ and northern China $\left(110^{\circ}-122^{\circ} \mathrm{E}, 35^{\circ}-40^{\circ} \mathrm{N}\right)$, respectively. The station rainfall dataset is provided by NCC.

summer northern China rainfall after the late 1970s (Wu and Wang 2002).

This study aims to investigate the possible linkages between SST anomalies in the southeastern and western Indian Ocean and the eastern China rainfall anomalies in the summer (June and July) of 2016. The organization of the text is as follows. Section 2 describes datasets, methods and model used in the present study. Section 3 presents the features of eastern China rainfall anomalies in the summer after decomposing the 2015/16 extreme El Niño into the EP El Niño-related and non-EP El Niño-related components. The separated influence of the southeastern and western tropical Indian Ocean SST anomalies on eastern China rainfall in the summer of 2016 is addressed in section 4 and section 5. Section 6 discusses the plausible reasons for the development of cold SST anomalies over western tropical Indian Ocean in the summer of 2016. A summary is given in section 7 .

\section{Datasets, methods, and model}

\section{a. Datasets}

Monthly precipitation datasets used in this study include 1) accumulated monthly station rainfall of 160 stations in mainland China starting from January 1951 to the present, which is derived from the National Climate Center (NCC) of the China Meteorological Administration; 2) monthly mean Climate Prediction Center (CPC) Merged Analysis of Precipitation (CMAP; Xie and Arkin 1997) on $2.5^{\circ} \times 2.5^{\circ}$ resolution grids from January 1979 to the present; and 3) Global Precipitation Climatology Project monthly precipitation (GPCP; Adler et al. 2003) in version 2 , which is available at a $2.5^{\circ} \times 2.5^{\circ}$ resolution from 1979 to the present. We adopt monthly Hadley Centre Sea Ice and SST dataset (HadISST; Rayner et al. 2003), which has a horizontal resolution of $1^{\circ} \times 1^{\circ}$ and spans the period from 1870 to the present.

The atmospheric variables used are obtained from the Japanese 55-year Reanalysis (JRA-55) dataset (Kobayashi et al. 2015) with a spatial resolution of $1.25^{\circ}$ from January 1958 to the present. Monthly oceanic current and temperature are derived from NCEP Global Ocean Data Assimilation System (GODAS) ocean reanalysis (NOAA/OAR/ESRL 2004). The dataset is available on a grid of $0.333^{\circ}$ latitude $\times 1.0^{\circ}$ longitude resolution starting from January 1980 to the present. Two sets of monthly mean shortwave radiation, longwave radiation, sensible heat flux, and latent heat flux are employed in the present study. One is from JRA-55 
and the other is from the TropFlux dataset (Praveen Kumar et al. 2012). The TropFlux dataset has a horizontal resolution of $1^{\circ} \times 1^{\circ}$ within $30^{\circ} \mathrm{S} \times 30^{\circ} \mathrm{N}$ and is available from January1979 to the present. A positive value of surface heat flux denotes that the flux is downward into the ocean, corresponding to oceanic heat gain, and vice versa.

\section{b. Methods}

Monthly anomalies of all variables are obtained by removing a 1981-2010 monthly mean climatology. To avoid the influence of global warming, their long-term linear trends are also removed. A regression analysis is applied to examine the relationship between pairs of variables during the period of 1979-2015. Its statistical significance is assessed by the two-sided Student's $t$ test. To quantitatively estimate the relative contributions of surface heat fluxes and oceanic processes to SST anomalies in the western tropical Indian Ocean, a mixed layer heat budget analysis is performed, following $\mathrm{He}$ and $\mathrm{Wu}$ (2013) and J. P. Chen et al. (2018).

Previous studies suggested that the EP and CP El Niños exert remarkably different impacts on eastern China rainfall during their decaying summer (Feng et al. 2011; Yuan and Yang 2012). The 2015/16 extreme El Niño is a mix-type event that possesses characteristics of both the EP and CP El Niños (Paek et al. 2017). We need to decompose the anomalies of this event into the EP El Niño-related and non-EP El Niño-related components to better understand the causes of the eastern China rainfall anomalies during the 2015/16 extreme El Niño. We use the cold tongue index (CTI) defined by Ren and Jin (2011) to represent the EP ENSO. Anomalies of all variables are then separated into an EP ENSO-related part and a non-EP ENSO-related part during 1979-2015 using the following formula:

$$
\begin{aligned}
Y_{\text {EP_ENSO-related_part }}(t) & =r(Y, \mathrm{CTI}) \times \mathrm{CTI}(t) \text { and } \\
Y_{\text {non-EP_ENSO-related_part }}(t) & =Y(t)-Y_{\text {EP_ENSO-related_part }}(t) .
\end{aligned}
$$

Here $r$ is the regression coefficient of a variable $Y$ with respect to the December-February value of the CTI. Note that the 2015/16 El Niño is excluded from the calculation of regression coefficient. The summer is considered to be June and July in this study.

\section{c. Model experiments}

To further confirm the impacts of SST anomalies over southeastern Indian Ocean and western tropical Indian Ocean on eastern China rainfall, three forced experiments are performed with the Community Atmosphere Model, version 5 (CAM5), the atmospheric component of the Community Earth System Model, version 1.2.2 (CESM1), developed by the National Center for Atmospheric Research. CAM5 includes a range of the latest enhancements and improvements in, for example, moist turbulence scheme, shallow convection scheme, stratiform microphysical processes, cloud macrophysics scheme, and three-mode modal aerosol scheme (Neal et al. 2012). The forced experiments are integrated for 22 years with a horizontal resolution of $1.25^{\circ}$ longitude $\times$ $0.9^{\circ}$ latitude and 26 vertical levels. We then use the last 20 years of the simulation to produce a 20 -member experiment. Each member is launched separately from 1 January of each of the last 20 years of the control simulation and is integrated for 12 months. During these ensemble simulations, a specific SST anomaly pattern is added to the climatological SSTs during May-July to force the CAM5.

\section{Eastern China rainfall anomalies in the decaying summer of the 2015/16 extreme EI Niño}

As shown in Fig. 1a, large positive rainfall anomalies appeared over MLRYR and northern China in the decaying summer (from June to July) of the 2015/16 extreme El Niño. The above-normal rainfall was also observed in MLRYR but not in northern China during the 1997/98 (Figs. 1b,d) and 1982/83 (Figs. 1c,e) extreme El Niños. The top three summer rainfall years (1998, 2016, and 1983) in this region occurred in the decaying summer of these three extreme El Niños (Fig. 2). However, northern China rainfall anomalies were very different among these three events. The rainfall was remarkably enhanced in the summer of 2016 (Figs. 1d,e), but it was slightly increased in the summer of 1998 and suppressed in the summer of 1983 . The northern China rainfall anomalies were even larger than the MLRYR rainfall anomalies in the decaying summer of the 2015/16 El Niño (Fig. 2).

These two bands of remarkable positive rainfall anomalies over northern China and MLRYR are also clearly shown in the GPCP (Fig. 3a) and CMAP (figure not shown) datasets during the summer of 2016. We then separate the total rainfall anomalies into the EP El Niño-related and non-EP El Niño-related rainfall anomalies using the regression method. Significant (at the $90 \%$ confidence level) positive rainfall anomalies over MLRYR are associated with the preceding winter EP El Niño (Fig. 3b), which is consistent with previous studies (Wu et al. 2003; Feng et al. 2011; Yuan and Yang 2012). The rainfall anomalies related to EP El Niño over MLRYR $\left(110^{\circ}-122^{\circ} \mathrm{E}, 27^{\circ}-32^{\circ} \mathrm{N}\right)$ account for $51.5 \%$, $55.5 \%$, and $61.6 \%$ of the total rainfall anomalies in the 


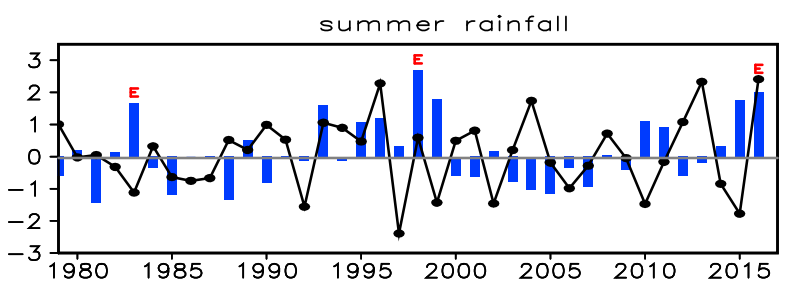

FIG. 2. Time series of normalized rainfall over the MLRYR (blue bars) and northern China (black line) in the summer (June and July). The decaying years of three extreme El Niños are marked by "E" on the top of the bar. The station rainfall dataset is provided by NCC.

summer of 2016 based on the NCC, CMAP, and GPCP datasets, respectively. Meanwhile, related to the EP El Niño component, significant positive rainfall anomalies also occurred over the tropical Indian Ocean and Maritime Continent, whereas significant negative anomalies occurred over northern India, the Indo-China Peninsula, and the South China Sea. Weak negative rainfall anomalies were observed in northern China, which is consistent with $\mathrm{Wu}$ and Wang (2002). After removing the influence of EP El Niño, positive rainfall anomalies over MLRYR became smaller, but positive rainfall anomalies over northern China were still large in the summer of 2016 (Fig. 3c). The non-EP El Niñorelated part of the rainfall anomalies was also pronounced over the western Indian Ocean and central-northern India. The in-phase relationship between rainfall anomalies over northern China and central-northern India is consistent with previous studies (e.g., Guo and Wang 1988; Kripalani and Kulkarni 2001; Wu 2002, 2017). The processes connecting rainfall anomalies over northern China, northern India, and the western tropical Indian Ocean will be further discussed in section 5.

We further examine the EP El Niño-related and nonrelated parts of SST and atmospheric circulation anomalies (Figs. 4-6). In the summer of 2016, positive SST anomalies appeared in the southeastern Indian Ocean while negative SST anomalies appeared in the western tropical Indian Ocean (Fig. 4a). Tropical Indian Ocean SST anomalies associated with EP ENSO feature a basinwide warming pattern (Fig. 5a), as indicated in previous studies (e.g., Feng et al. 2011; Yuan and Yang 2012; Tao et al. 2014). After removing the EP ENSO-related part, the Indian Ocean SST anomalies are characterized by an east-west contrast pattern with warm anomalies in the southeastern Indian Ocean and cold anomalies in the western tropical Indian Ocean (Fig. 6a). As compared with the non-EP ENSO-related part, the EP ENSO-related part contributes mostly to the warm SST anomalies over the southeastern Indian Ocean during the summer of 2016 (cf. Fig. 5a and Fig. 6a). Figures 4-6 together indicate that, while the

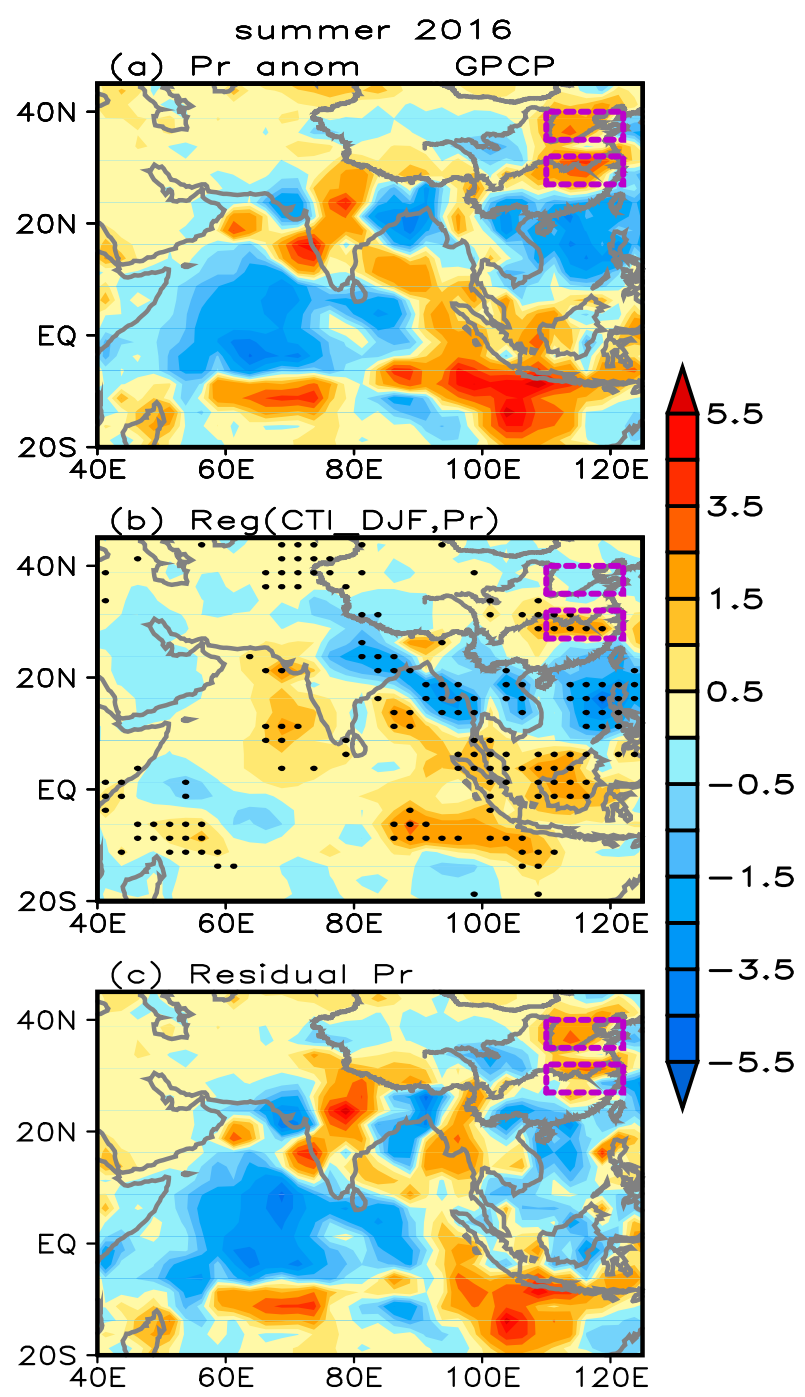

FIG. 3. (a) Total rainfall anomalies, (b) EP El Niño-related parts of rainfall anomalies, and (c) non-EP El Niño-related parts of rainfall anomalies in the summer of $2016\left(\mathrm{~mm} \mathrm{day}^{-1}\right)$. Dots in (b) denote the regions with regression that is significant at the $90 \%$ confidence level. The reanalysis rainfall dataset is adopted from GPCP. The southern and northern dashed rectangles represent the regions of MLRYR and northern China, respectively.

warm SST anomalies observed during the summer of 2016 in the southeastern Indian Ocean are closely related to the EP El Niño component of the 2015/16 El Niño, the cold SST anomalies in the western tropical Indian Ocean are independent from the EP component.

Tropical SST variations are one of the most important external forcings to disturb atmospheric circulations. Figure 5a shows that the EP ENSO-related tropical Indian Ocean warming is overlaid by an anomalous lower-level cyclonic wind, an anomalous ascent motion at $500-\mathrm{hPa}$, and an anomalous upper-level divergence (Figs. 5b,c). The circulation anomalies represent an 

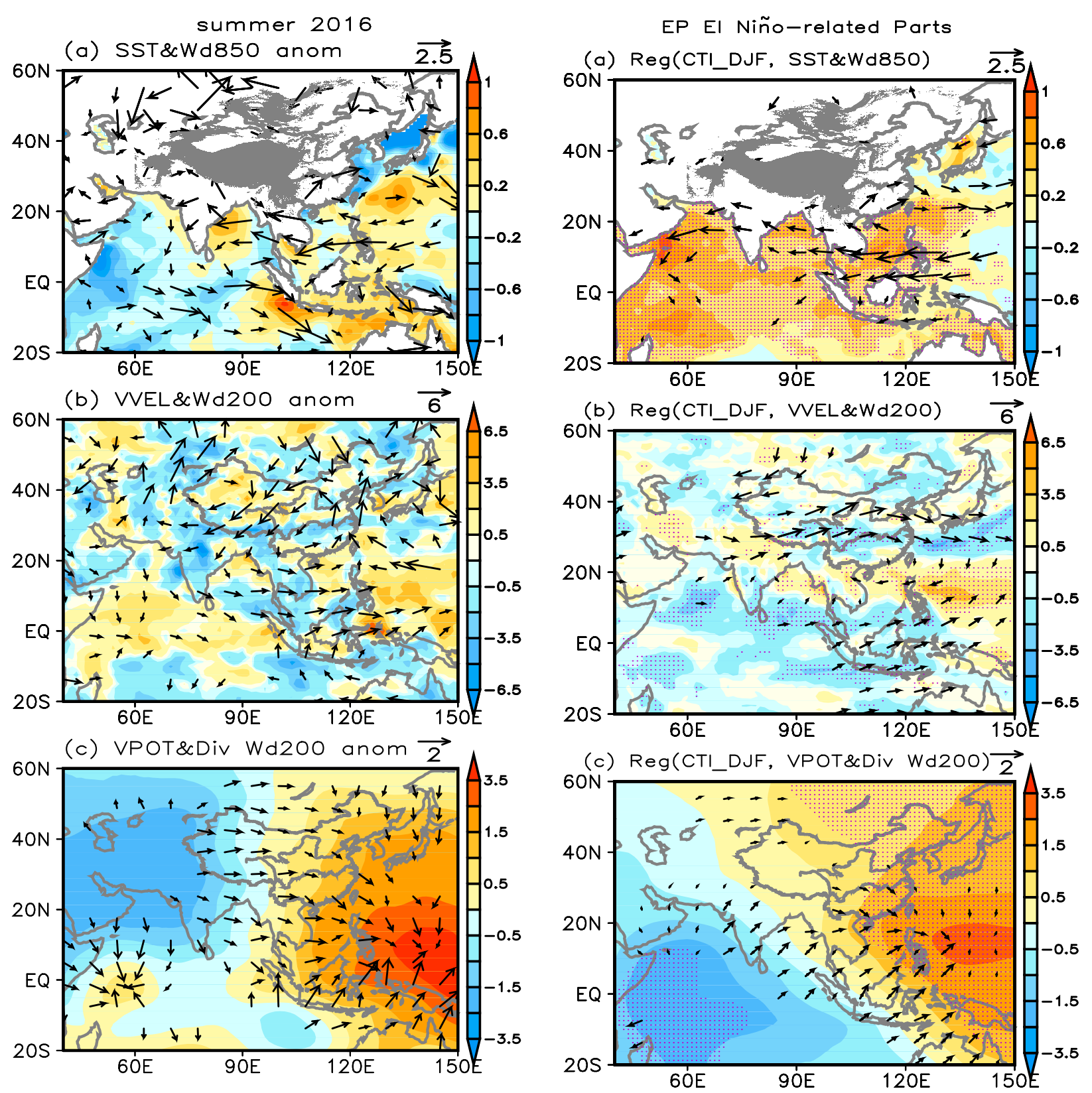

FIG. 4. Anomalies of (a) SST (shading; ${ }^{\circ} \mathrm{C}$ ), 850-hPa winds (vectors; $\mathrm{m} \mathrm{s}^{-1}$ ), (b) 500-hPa $p$-vertical velocity (shading; $10^{-2} \mathrm{~Pa} \mathrm{~s}^{-1}$ ), 200-hPa winds (vectors; $\mathrm{m} \mathrm{s}^{-1}$ ), (c) 200-hPa velocity potential (shading; $10^{6} \mathrm{~m}^{2} \mathrm{~s}^{-1}$ ), and corresponding divergent winds (vectors; $\mathrm{m} \mathrm{s}^{-1}$ ) in the summer of 2016 .

atmospheric response to tropical Indian Ocean warming, according to Lindzen and Nigam (1987). Over the Pacific, the EP El Niño is well known to be associated with an anomalous lower-level anticyclone covering the western North Pacific and southeastern China (Wu et al. 2003; Zhang et al. 2017). The anomalous southwesterly winds along the northwest flank of this anomalous anticyclone provide sufficient moisture into the MLRYR

FIG. 5. As in Fig. 4, but for the EP ENSO-related part in the summer of 2016. Dots denote the regions of (a) SST, (b) $p$-vertical velocity, and (c) velocity potential with regression that is significant at the $90 \%$ confidence level. Only the regression coefficients of winds exceeding the $90 \%$ confidence level are plotted.

region to enhance the rainfall there. Previous studies have shown that the anomalous western North Pacific anticyclone is maintained from the developing to the decaying phases of the El Niño to impact East Asian climate via local air-sea interactions (Wang et al. 2000) and remote forcing from the El Niño-induced Indian Ocean warming (Yang et al. 2007; Li et al. 2008; Wu et al. 2009; Xie et al. 2009). It should be noted that a 
non-EP EI Niño-related Parts
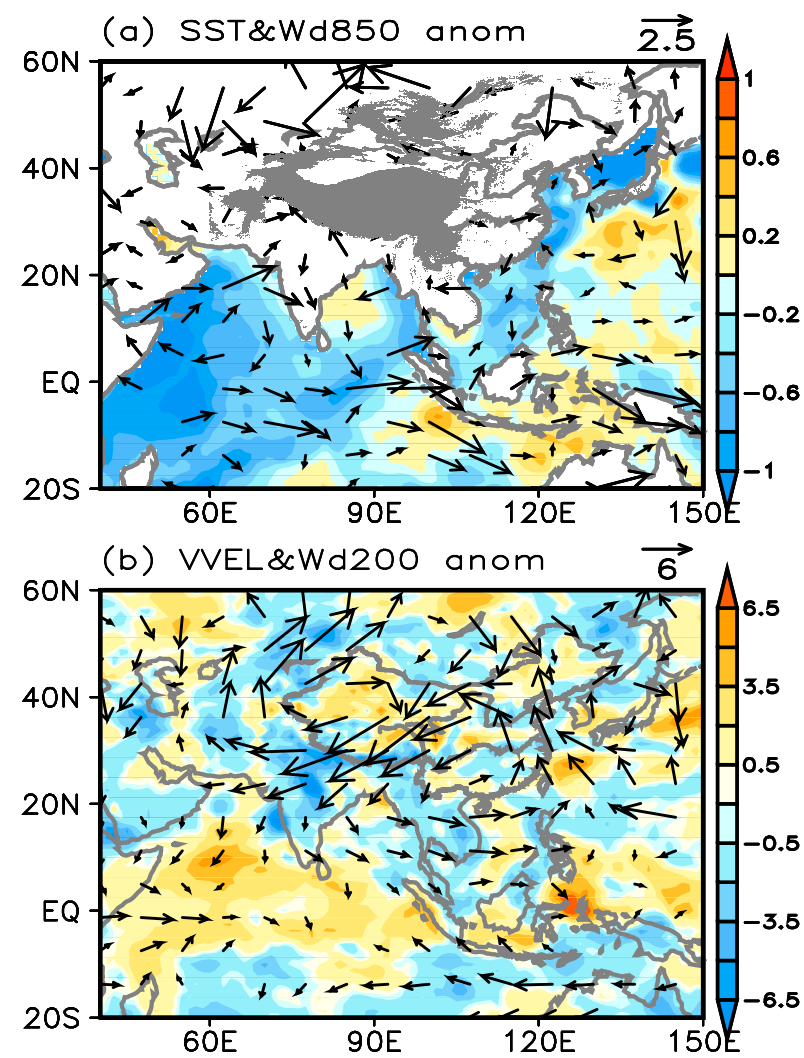

(c) VPOT\&Div Wd200 anom $\overrightarrow{2}$

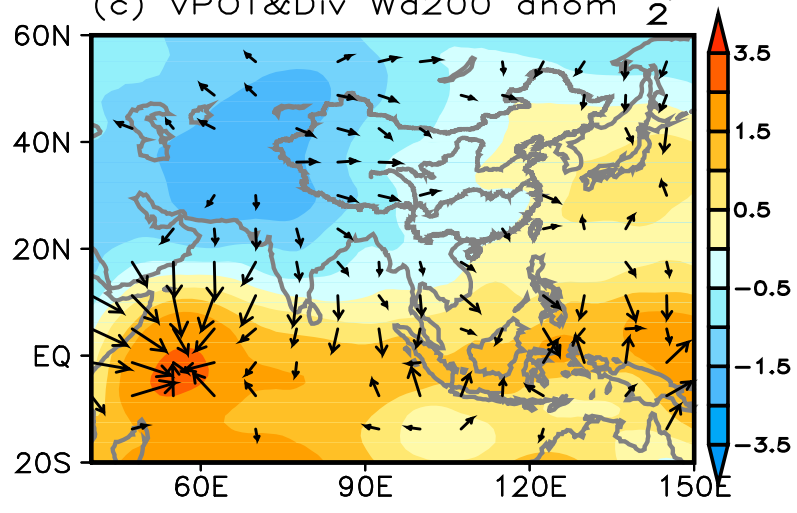

FIG. 6. As in Fig. 4, but for the non-EP ENSO-related part in the summer of 2016.

weak anomalous cyclone is observed over northeast Asia, which is responsible for weak below-normal rainfall over northern China.

In the non-EP ENSO-related part of summer 2016, the anomalous atmospheric circulations were dominated by a low-level anomalous anticyclonic wind over the western tropical Indian Ocean, an anomalous descent motion at 500-hPa, and anomalous upper-level convergence (Fig. 6). These circulation features appear to be an atmospheric response to the cold SST anomalies underneath. The anomalous southwesterly winds in the northwest flank of the low-level anticyclone reinforces Indian summer monsoon, while the upper-level divergent flow also helps the upper-level monsoon flow to move from the Indian Peninsula to the western Indian Ocean. The enhanced ascents and descents, respectively, over central-northern India and the western tropical Indian Ocean form a regional meridional circulation pattern. Through this anomalous atmospheric circulation, the cooling anomaly in the western tropical Indian Ocean can increase the central-northern India rainfall (Fig. 3c). The increased rainfall could excite an upper-level wave train that propagates zonally along $30^{\circ}-$ $50^{\circ} \mathrm{N}$ (Fig. 6b). The wave train consists of two anomalous anticyclones centering over the northwest of India and northeast Asia and an anomalous cyclone in between. On the west flank of the anomalous northeast Asia anticyclone, the anomalous northern China ascent is mainly caused by both the anomalous vorticity advection by the basic-state westerly winds and the mean temperature advection by the anomalous southerly winds (Wei et al. 2014, 2017). The anomalous anticyclone over northeast Asia features an equivalent barotropic structure (cf. Figs. 6a,b). The surface part of the anomalous anticyclone transports moisture into northern China leading to positive rainfall anomalies there. Previous studies (e.g., Wu and Wang 2002; Wu 2002) have noticed the vital role of anomalous Indian summer heating in triggering the midlatitude Asian wave pattern. Such a wave pattern acts as a bridge to connect summer rainfall variability over northern China and India (Krishnan and Sugi 2001; Wu and Wang 2002; Wu 2002, 2017). Western tropical Indian Ocean SST anomalies provide a way to activate this tropical-extratropical rainfall connectivity.

\section{Role of southeastern Indian Ocean SST anomalies in MLRYR rainfall in the summer}

Our results so far indicate that maintaining a pronounced western North Pacific anomalous anticyclone is crucial to an increase of MLRYR rainfall during the El Niño decaying summer. The basinwide tropical Indian Ocean warming is one of the key contributors to this maintenance, which was observed during the 1982/83 and 1997/98 extreme El Niño events. However, the basinwide warming disappeared unexpectedly during the summer of 2016 and was replaced by a western tropical Indian Ocean cooling and a southeastern Indian Ocean warming (Fig. 4a). Tropical Indian Ocean SST anomalies during the summer of 2016 exhibited a signature of the negative Indian Ocean dipole (IOD; Saji et al. 1999). However, we find no significant simultaneous correlation coefficients between IOD and rainfall over MLRYR (0.21) and northern China (-0.24) during 1979-2016. 


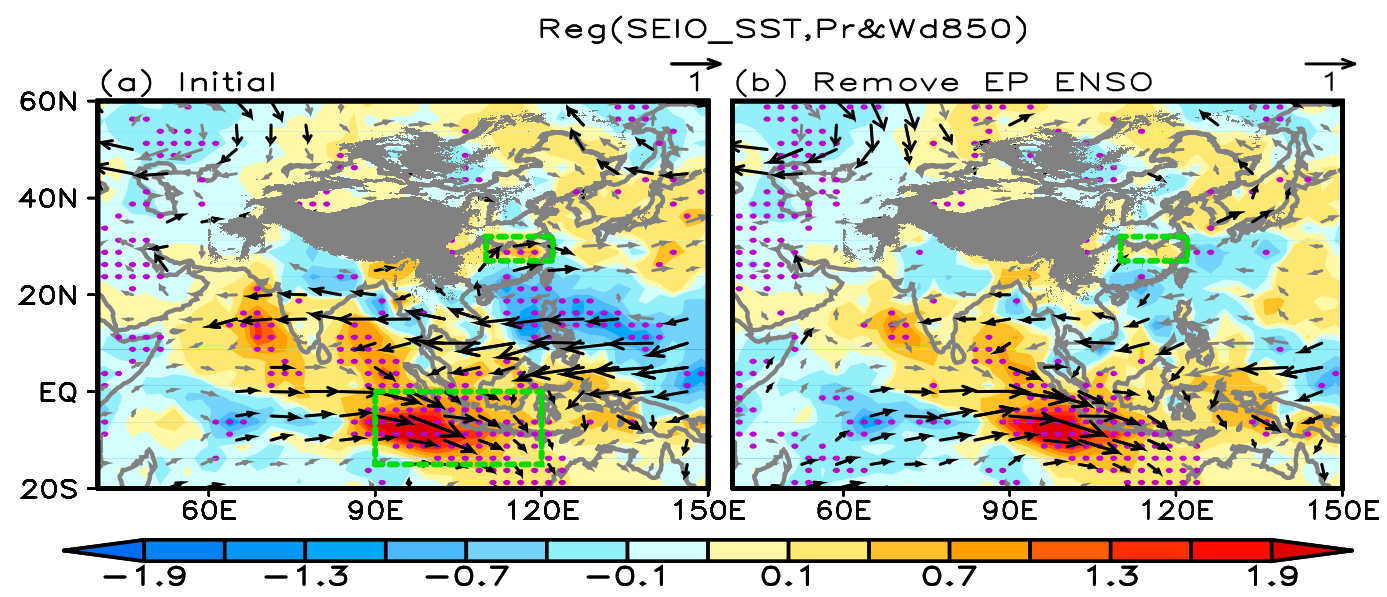

FIG. 7. (a) Regression pattern of rainfall (shading; $\mathrm{mm} \mathrm{day}^{-1}$ ) and $850-\mathrm{hPa}$ winds (vectors; $\mathrm{m} \mathrm{s}^{-1}$ ) with respect to the normalized southeastern Indian Ocean SST index in the summer for the period of 1980-2015. (b) As in (a), but for non-EP ENSO-related parts. Dots denote the regions of rainfall with regression that is significant at the $90 \%$ confidence level. The regression coefficients of winds exceeding the $90 \%$ confidence level are highlighted in boldface. The southern and northern rectangles represent the regions of the southeastern Indian Ocean and MLRYR, respectively.

SST anomalies in the southeastern Indian Ocean were as large as 1.73 standard deviations during the summer of 2016. To understand the influence of these SST anomalies, we regress summer rainfall, 850-hPa winds, and SST anomalies in the Indo-western Pacific region onto the area-mean SSTs over the southeastern Indian Ocean $\left(90^{\circ}-120^{\circ} \mathrm{E}, 15^{\circ} \mathrm{S}-0^{\circ}\right)$ during $1980-2015$ (Fig. 7a). It can be seen that significant lower-level anticyclone dominates southeastern China and the western North Pacific together with an enhanced rainfall over MLRYR. When the EP ENSO-related part is removed, the anomalous anticyclone and the positive rainfall anomalies over MLRYR decrease (Fig. 7b). Both the EP ENSO-related and the non-EP ENSO-related parts of southeastern Indian Ocean SST anomalies influenced the anomalous western North Pacific circulation and induced MLRYR rainfall anomalies in the same way, but the EP ENSOrelated part of southeastern Indian Ocean SST anomalies made the greater contribution to summer MLRYR rainfall than the non-EP ENSO-related part in the summer of 2016. Wu et al. (2012) indicated the southeastern Indian Ocean SST anomalies play an important role in anomalous circulation over western North Pacific. Chen et al. (2017) further demonstrated with CAM5 experiments that warm SST anomalies in the southeastern Indian Ocean, independent of ENSO, can trigger an anomalous lower-level anticyclone over southeastern China and the western North Pacific. It can be inferred that, in the summer of 2016, warm southeastern Indian Ocean SST anomalies themselves and those related to EP El Niño together increase MLRYR rainfall by intensifying the anticyclone over southeastern China and the western North Pacific.
To demonstrate the influence of SST anomalies in the southeastern Indian Ocean on the MLRYR rainfall anomalies, we conduct a pair of forced experiments. In the control run, the CAM5 is forced with the climatological mean seasonal cycle of SSTs prescribed from January to December. In the 20-member experiment, anomalous southeastern Indian Ocean warming is added to the climatological SST cycle superimposed to force the CAM5. Each member is integrated from January to December with the SST anomalies added only during May to July. The SST anomaly patterns used in the experiment (Figs. 8a-c) are extracted from the SST anomalies observed during May to July of 2016. Responding to warm SST anomalies in the southeastern Indian Ocean, an anomalous anticyclone at the lower level occurs over western North Pacific and significant above-normal rainfall is seen over MLRYR. The results of numerical experiments broadly support the influence of the southeastern Indian Ocean SST anomalies from May to July on MLRYR summer rainfall. It is noted that there are still few differences between the numerical experiments and the observations. The positive rainfall anomalies in simulation are opposite to the observations in southern China (Fig. 8d vs Fig. 3a). It may be related to the intensity and location of the anomalous western North Pacific anticyclone, which is weak and located more southward in the model experiment forced by the southeastern Indian Ocean SST anomalies solely. Except for the remote forcing of tropical Indian Ocean SST, the local air-sea interaction exerts considerable influence on the anomalous western North Pacific anticyclone persisting from the El Niño decaying spring to 

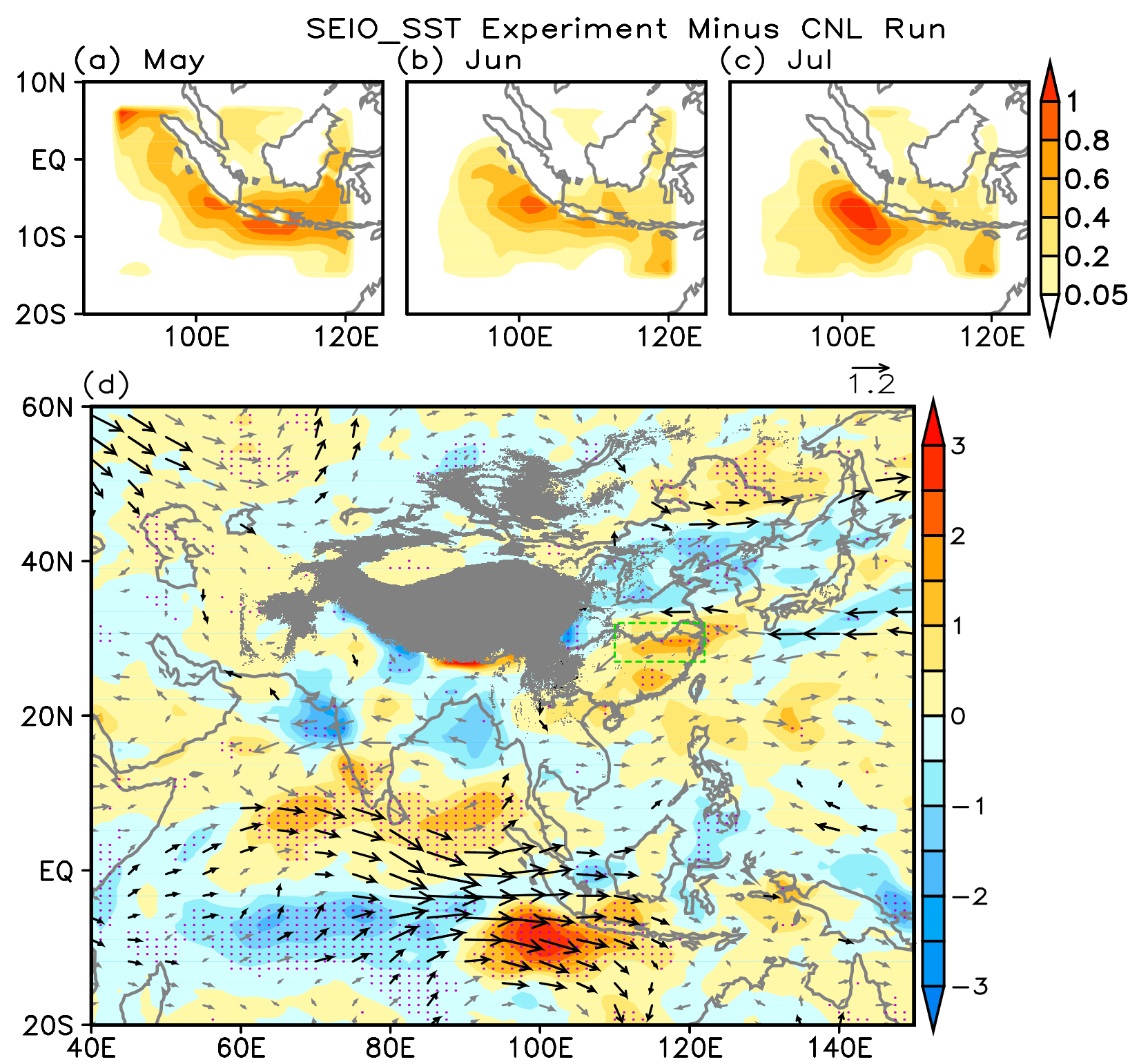

FIG. 8. SST anomaly $\left({ }^{\circ} \mathrm{C}\right.$ ) distribution in (a) May, (b) June, and (c) July for the southeastern Indian Ocean SST experiment. Also shown are (d) composite differences of rainfall (shading; $\mathrm{mm}$ day $^{-1}$ ) and $850-\mathrm{hPa}$ winds (vectors; $\mathrm{m} \mathrm{s}^{-1}$ ) in the summer between the southeastern tropical Indian Ocean SST experiment and the CAM5 control run. Dots denote the regions of rainfall differences that are significant at the $90 \%$ confidence level. The wind differences exceeding the $90 \%$ confidence level are highlighted in boldface. The green-dashed rectangle represents the region of MLRYR.

summer (Wang et al. 2000), which is not considered in our model experiments.

\section{Role of western tropical Indian Ocean SST anomalies in northern China rainfall in the summer}

As shown earlier, the increased rainfall over northern China and central-northern India were accompanied with deficient rainfall over the western tropical Indian
Ocean, corresponding to negative local SST anomalies in the summer of 2016 (see Figs. 3a and 4a). To further explore the forcing and response relationship between northern China rainfall and western tropical Indian Ocean SST, we show in Figs. 9a-c the SST anomaly during May-July separately regressed onto the normalized summer rainfall averaged over northern China $\left(110^{\circ}-122^{\circ} \mathrm{E}, 35^{\circ}-40^{\circ} \mathrm{N}\right)$ during $1980-2015$. The regressions are characterized by significant negative SST anomalies in the western tropical Indian Ocean that 

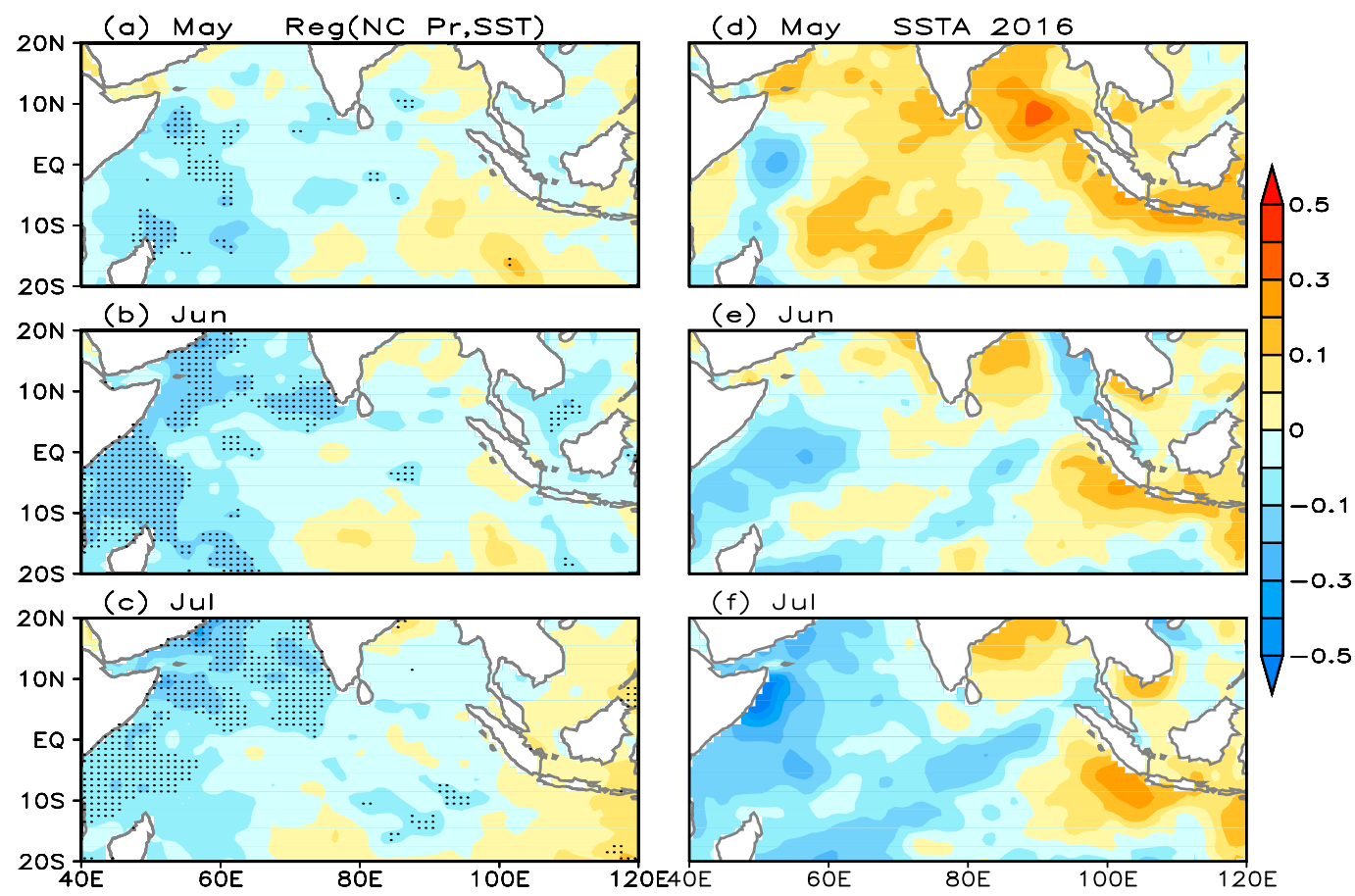

FIG. 9. Regression pattern of SST $\left({ }^{\circ} \mathrm{C}\right)$ in (a) May, (b) June and (c) July with respect to the normalized northern China rainfall index in summer for the period of 1980-2015. In (a)-(c), dots denote the regions of SST with regression significant that are at the $90 \%$ confidence level. Also shown are SST anomalies in (d) May, (e) June and (f) July 2016.

persist from May to July. A similar evolution of SST anomalies was observed from May to July in 2016 (Figs. 9d-f). We also note from Figs. 9a-c that there are no significant regressions in the southeastern Indian Ocean. Our regression results imply that western tropical Indian Ocean SST anomalies exert a strong impact on northern China rainfall and that the rainfall anomalies are independent on southeastern Indian Ocean SST anomalies.

In the discussion of Figs. 4-6 we have described possible tropical-midlatitude processes that can enable the western tropical Indian Ocean SSTs to impact the North China rainfall through a case study (i.e., summer of 2016). To further confirm the processes, in Figs. 10a and $10 \mathrm{~b}$ we regress the rainfall, 200-Pa wind, and $850-\mathrm{hPa}$ wind, and 500-hPa $p$-vertical velocity anomalies onto the normalized SST averaged over the western tropical Indian Ocean $\left(40^{\circ}-60^{\circ} \mathrm{E}, 20^{\circ} \mathrm{S}-10^{\circ} \mathrm{N}\right)$ in the summer of 1980-2015. To examine the circulation features associated with the western tropical Indian Ocean cooling, the signs of the SST anomalies were reversed in the regression. We find that the main circulation features appear in the regressions to be similar to those shown in the non-EP El Niño part (Fig. 6). The regressions show that the western tropical Indian Ocean cooling is related to cross-equatorial southwesterly winds at $850-\mathrm{hPa}$ from western tropical Indian Ocean to Arabian Sea and India, which enhance Indian summer monsoon and transport excessive warm moisture to central-north India. Similar to what we observed in Fig. 6, the cold anomalies in the western Indian Ocean are accompanied with a zonal wave train along $30^{\circ}-50^{\circ} \mathrm{N}$ at $200 \mathrm{hPa}$, which consists of two anomalous anticyclones over northwest India and northeast Asia and a weak anomalous cyclone in between. Strong barotropic anticyclonic winds dominate northeastern China, the Korean Peninsula, the Sea of Japan, and regions of Japan. On its southwestern flank, anomalous southeasterly winds transport water vapor from the East China Sea to produce positive rainfall anomalies over northern China. The 500-hPa vertical motion anomalies also confirm that the anomalous cooling in the western tropical Indian Ocean induces anomalous descents over western tropical Indian Ocean and anomalous ascents over central-northern India and northern China. Our regressions show that the in-phase relationship between rainfall anomalies over northern China and central-northern India is established through excitation of the midlatitude Asian teleconnection pattern associated with anomalous central-northern Indian heating, and that central-north India heating is closely related to an anomalous cooling in the western tropical Indian Ocean SST. 

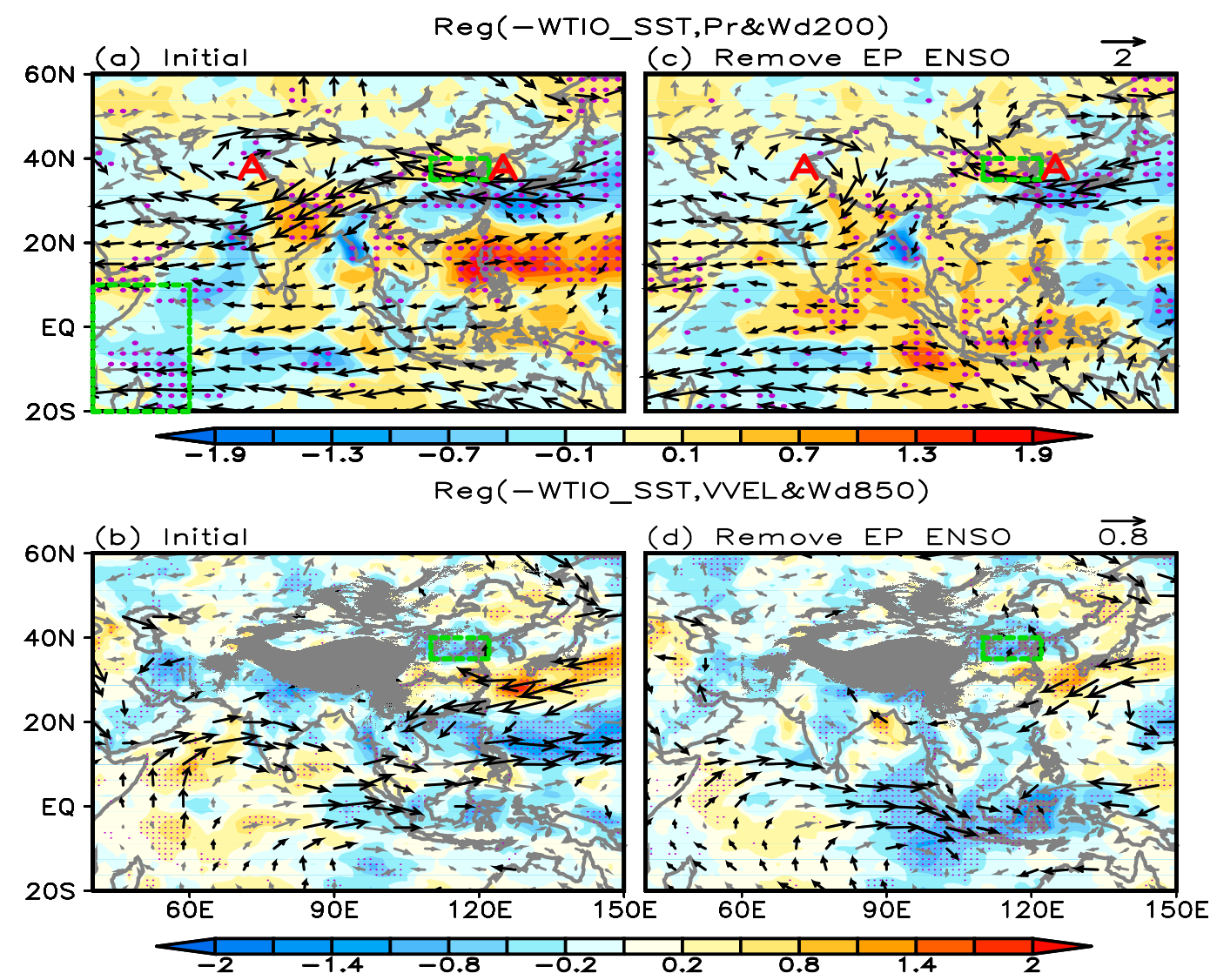

FIG. 10. Regression pattern of (a) rainfall (shading; $\mathrm{mm} \mathrm{day}^{-1}$ ), 200-hPa winds (vectors; $\mathrm{m} \mathrm{s}^{-1}$ ), (b) 500-hPa $p$-vertical velocity (shading; $10^{-2} \mathrm{~Pa} \mathrm{~s}^{-1}$ ), and $850-\mathrm{hPa}$ winds (vectors; $\mathrm{m} \mathrm{s}^{-1}$ ) with respect to the normalized western Indian Ocean SST index (multiplied by -1; the south rectangle) in summer for the period of 1980-2015. (c),(d) As in (a) and (b), but for the non-EP ENSO-related part. Dots denote the regions of rainfall [in (a) and (b)] and 500-hPa $p$-vertical velocity [in (c) and (d)] with regression that are significant at the $90 \%$ confidence level. The regression coefficients of winds exceeding the $90 \%$ confidence level are highlighted in boldface. The "A" labels denote an anomalous anticyclone. The southern and northern rectangles represent the regions of the western tropical Indian Ocean and northern China, respectively.

To show the independent roles of the western tropical Indian Ocean SST anomalies from EP ENSO, we repeat the regression but with the EP ENSO-related part removed from all variables. As shown in Figs. 10c and 10d, central-northern India rainfall anomalies are still closely related to western tropical Indian Ocean SST anomalies. Moreover, significantly increased rainfall over centralnorthern India could be connected with increased northern China rainfall through the even more remarkable midlatitude wave train pattern. The regression results further confirm that the non-EP El Niño part of the circulation and rainfall anomalies observed during the summer of 2016 (Figs. 3c and 6) are related to the western tropical Indian Ocean cooling.

To further demonstrate the cause and effect relationship between the western tropical Indian Ocean cooling and the rainfall/circulation variations, we also conduct a forced experiment similar to the southeastern Indian Ocean SST experiment, except that the western tropical Indian Ocean cooling is added to the climatological SST cycle during May-July (Fig. 11). Figures 12a and $12 \mathrm{~b}$ show the differences between the last 20 years' averages of the control simulation and the ensemble means of the 20-member experiment with the western tropical Indian Ocean cooling. The experiment reproduces most of the key features at 850 and $200 \mathrm{hPa}$ that we described in Figs. 6 and 10 that link the western tropical Indian Ocean cooling to the increased North China rainfall. In particular, the upper and lower-level anomalous winds suggest an anomalous southwestnortheast vertical circulation that links the western tropical Indian Ocean and central-northern India. This is confirmed by Fig. 12c, which shows differences in meridional winds and vertical $p$ velocity along a cross 

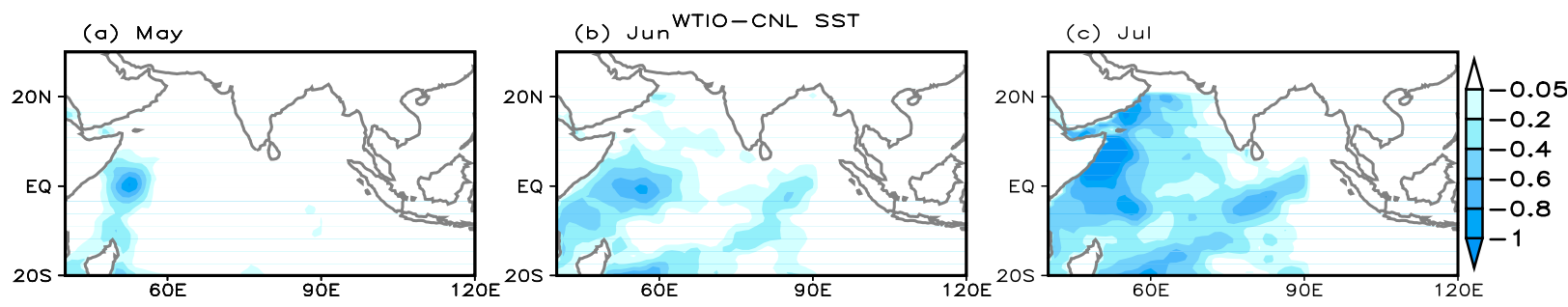

FIG. 11. SST anomaly $\left({ }^{\circ} \mathrm{C}\right.$ ) distribution in (a) May, (b) June, and (b) July for the western tropical Indian Ocean SST experiment.

section from $5^{\circ} \mathrm{N}, 55^{\circ} \mathrm{E}$ to $20^{\circ} \mathrm{N}, 75^{\circ} \mathrm{E}$. Clearly, the vertical circulation directly connects the anomalous descent over the western tropical Indian Ocean and the anomalous ascent over central-northern India. These numerical experiments demonstrate that negative SST anomalies over the western tropical Indian Ocean force a local meridional circulation to increase monsoon rainfall in central-northern India, which then trigger a monsoon-midlatitude wave train to result in increased rainfall over North China. As suggested by previous studies (Wu 2002; Wu and Wang 2002; Ding and Wang 2005; Wu 2017), the anomalous heating associated with anomalous Indian summer rainfall plays an important role in the development of the wave pattern over the midlatitudes of Asia. The anomalous heating triggers an anomalous anticyclone northwest of the Tibetan Plateau in the upper troposphere as the Gill-type Rossby wave response (Rodwell and Hoskins 1996). The anomalous anticyclone corresponding to divergence of wave activity flux, acting as a Rossby wave source, influences downstream East Asia through Rossby wave propagation along the perturbed midlatitude westerly (Wu and Wang 2002; Wu et al. 2003; Ding and Wang 2005; Wu 2017).

\section{The development of western tropical Indian Ocean SST anomalies}

During the three extreme El Niño events, the evolution of SST anomalies in the western tropical Indian Ocean from peak to decaying phases displays common features and noticeable differences. As shown in Fig. 13a, warm SST anomalies persisted in this region from the developing winter to the decaying summer during the 1982/83 and 1997/98 events. In contrast, the SST anomalies changed from positive into negative after the decaying May during the 2015/16 event. Afterward, western tropical Indian Ocean cooling persisted through the summer. To understand how the anomalous cooling was produced in the summer of 2016, in Figs. 13b and 13c we contrasted the ocean mixed layer heat budget in the western tropical Indian Ocean $\left(40^{\circ}-60^{\circ} \mathrm{E}, 20^{\circ} \mathrm{S}-10^{\circ} \mathrm{N}\right)$ among the three extreme El Niños. The analyses were applied only to the decaying May of the events in which the western tropical Indian Ocean came into being anomalous cooling. For all three events, the net surface heat flux term was the biggest contributor to the SST change in the region, whereas horizontal and vertical advection terms played minor roles (Fig. 13b). For the surface heat flux term, the shortwave radiation flux (SWR) anomaly was negative and its cooling effect of SWR was offset by penetrative shortwave radiation flux, longwave radiation flux and sensible heat flux to some extent for all three extreme events. For the 1982/83 and $1997 / 98$ events, the surface heat flux term was dominated by the cancellation between the negative SWR anomalies and the positive latent heat flux (LHF) anomalies (Fig. 13c). The positive anomalies in LHF made a dominant positive contribution to western tropical Indian Ocean warming. In contrast, for the 2015/16 event the LHF anomalies were weak negative. It means that the positive effect of LHF on western tropical Indian Ocean warming as in May 1983 and 1998 does not work in May 2016. Due to the reduced LHF anomalies, the net surface heat flux term during May 2016 was dominated by the SWR anomaly to turn negative (Fig. 13c). Thus, the western tropical Indian Ocean cooling in the early summer of 2016 is attributed to a reduction of positive anomaly in the LHF in the region. The above analyses are based on the flux dataset from the JRA-55 dataset. We repeated the analyses with the TropFlux dataset and obtained similar results (not shown).

Positive anomalies in LHF imply weaker evaporations from the ocean surface, which are often associated with reduced surface wind speeds. A reduction of the positive LHF anomalies during May 2016 should be understood as an increase of the surface winds during this El Niño event. This is confirmed by Figs. 13d-f, which show that when LHF anomalies over the western tropical Indian Ocean are far smaller in May 2016 than in May 1983 and 1998 (Fig. 13c), the anomalous southwesterly winds over the western tropical Indian Ocean should strengthen the background southwest monsoon in May 2016 and increase local evaporation to cool down local SSTs. On the contrary, in May 1983 and 1998, anomalous northeasterly 
WTIO_SST Experiment Minus CNL Run

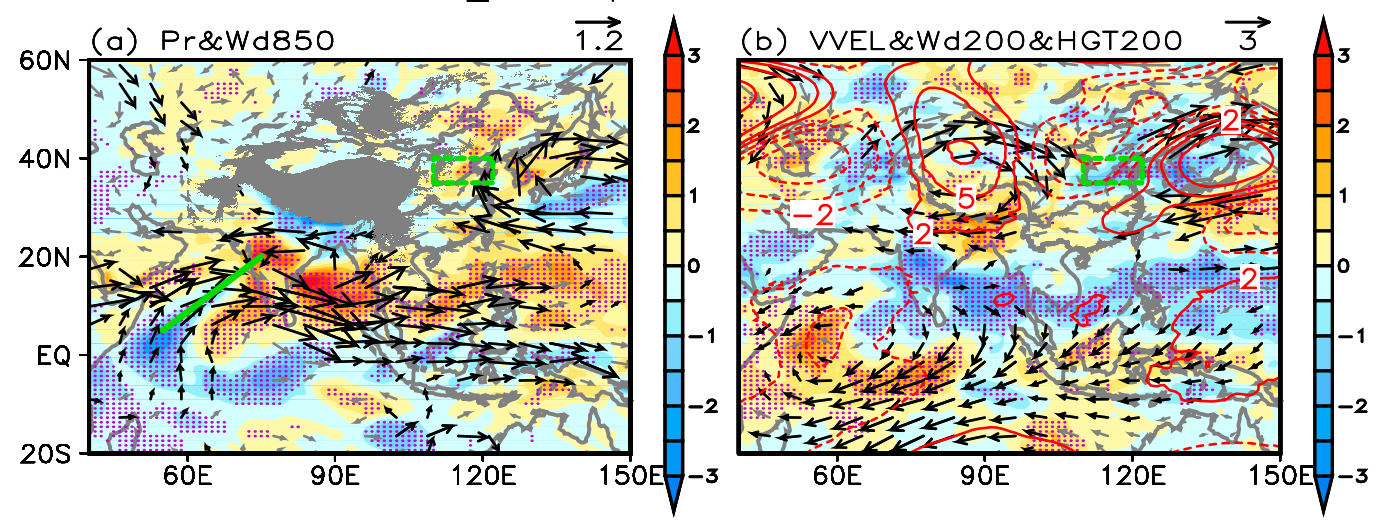

(c) along $\left(5^{\circ} \mathrm{N}, 55^{\circ} \mathrm{E}\right)$ to $\left(20^{\circ} \mathrm{N}, 75^{\circ} \mathrm{E}\right)$

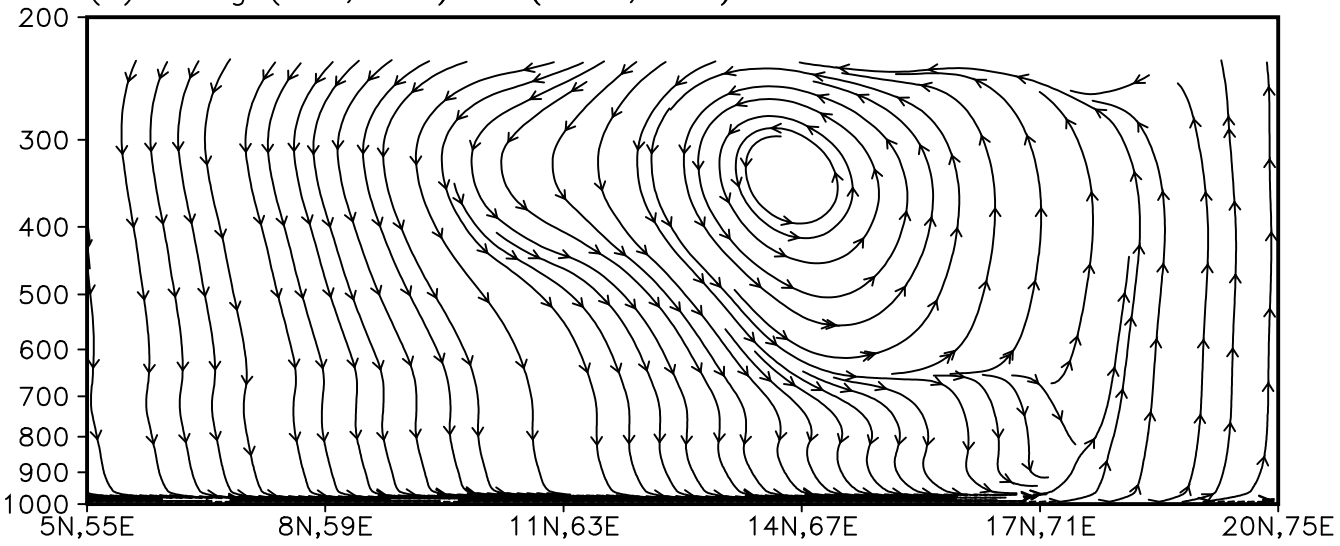

FIG. 12. Composite differences of (a) rainfall (shadings; $\mathrm{mm} \mathrm{day}^{-1}$ ), 850-hPa winds (vectors; $\mathrm{m} \mathrm{s}^{-1}$ ), (b) 500-hPa $p$-vertical velocity (shading; $10^{-2} \mathrm{~Pa} \mathrm{~s}^{-1}$ ), 200-hPa winds (vectors; $\mathrm{m} \mathrm{s}^{-1}$ ), and zonal anomalies (minus zonal mean) geopotential height (contours; gpm) in the summer between the western tropical Indian Ocean SST experiment and the CAM5 control run. Dots denote the regions of rainfall [in (a)] and $p$-vertical velocity [in (b)] differences significant at the $90 \%$ confidence level. The wind differences exceeding the $90 \%$ confidence level are highlighted in boldface. The contour interval is $\pm 2, \pm 5, \pm 10$, and \pm 20 . (c) Composite differences of vertical circulation consisting of meridional wind $\left(\mathrm{m} \mathrm{s}^{-1}\right)$ and vertical $p$-velocity $\left(-0.01 \mathrm{~Pa} \mathrm{~s}^{-1}\right)$ from $5^{\circ} \mathrm{N}, 55^{\circ} \mathrm{E}$ to $20^{\circ} \mathrm{N}, 75^{\circ} \mathrm{E}$ [the green line shown in (a)] in the summer between the western tropical Indian Ocean SST experiment and the CAM5 control run. The rectangle represents the region of northern China.

winds (Figs. 13e,f) should weaken climatological southwesterly winds and facilitate the persistence of anomalous warming underneath. From the evolution of climatological meridional winds, the climatological southerly winds appear in April and gradually strengthen in summer (figure not shown). For previous two extreme El Niños, the southerly winds obviously weakened in decaying May (Figs. 13e,f), accompanying with an increase of LHF (Fig. 13c). The increased LHF contributed to western tropical Indian Ocean warming via wind-evaporationSST feedback. During the 2015/16 event, southerly winds dramatically enhanced in decaying May (Fig. 13d), which was responsible for the reduced LHF and the sharp decline of western tropical Indian Ocean SST anomalies (Figs. 13a,c). The persisting anomalous southerly winds kept western tropical Indian Ocean cooling in early summer. Thus, the local wind differences among three extreme El Niños partly contribute to the development of western tropical Indian Ocean SST anomalies.

Above analysis indicates the differences of SST change in the western tropical Indian Ocean between the 2015/16 El Niño and the other two extreme El Niño events are controlled by local circulations in the decaying May. There are two plausible reasons to explain the differences of circulations in the western tropical Indian Ocean between the 2015/16 El Niño and the other two extreme El Niño events. The first is the 2015/16 event decays faster than the other two events (J. P. Chen et al. 2018), and the second is that the 2015/16 events has its peak SST anomalies located more westward than the other two events (Paek et al. 2017). According to Ren et al. (2016), the magnitude of warm SST anomalies in the western 

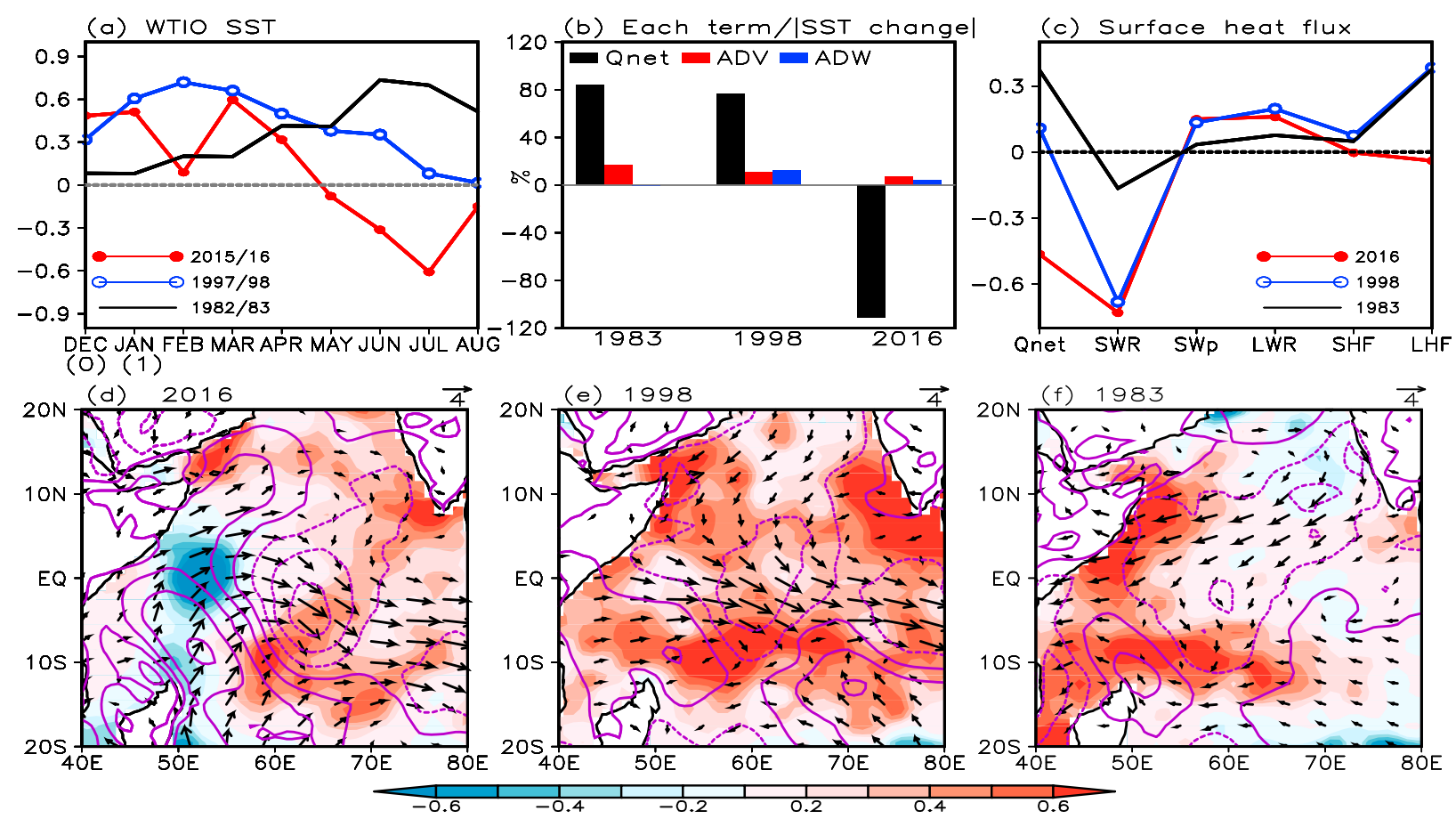

FIG. 13. (a) Evolution of SST $\left({ }^{\circ} \mathrm{C}\right)$ anomalies averaged over the western tropical Indian Ocean $\left(40^{\circ}-60^{\circ} \mathrm{E}, 20^{\circ} \mathrm{S}-10^{\circ} \mathrm{N}\right)$ from December to the following August in 1982/83 (black line), 1997/98 (blue line), and 2015/16 (red line) extreme El Niños. The 0 and 1 stand for the developing and decaying year of El Niño, respectively. (b) Relative contributions (\%) of anomalies of net surface heat flux (Qnet; black bars), horizontal advection (ADV; red bars) and vertical advection (ADW; blue bars) averaged over the western tropical Indian Ocean in May 2016, 1998, and 1983 to absolute value of SST change. (c) Anomalies of surface heat flux anomalies $\left({ }^{\circ} \mathrm{C}\right.$ month $\left.{ }^{-1}\right)$ including shortwave radiation flux (SWR), penetrative shortwave radiation flux (SWp), longwave radiation flux (LWR), sensible heat flux (SHF), and latent heat flux (LHF) averaged over the western tropical Indian Ocean in May 1983 (black line), 1998 (blue line), and 2016 (red line). Surface heat flux datasets are adopted from JRA-55. Also shown are SST (shading; ${ }^{\circ} \mathrm{C}$ ), 1000-hPa wind (vectors; $\mathrm{m} \mathrm{s}^{-1}$ ), and 1000-hPa meridional wind (contours; $\mathrm{m} \mathrm{s}^{-1}$ ) anomalies in (d) May 2016, (e) 1998, and (f) 1983. The contour interval is 1.

tropical Indian Ocean should be larger when the El Niño decays slow in the Pacific, since anomalous Walker circulation over the Indian and Pacific Ocean gets stronger from winter to summer. Based on their finding, the fasterdecaying 2015/16 event is less capable of inducing warm anomalies in the western tropical Indian Ocean. This may be the reason why cold anomalies occurred in this region during this event. As for the location difference, previous studies showed that the more westward-displaced El Niño SST anomalies can weaken the anomalous cyclonic winds typically induced by the EP El Niño over the Indian Ocean. The weakened wind anomalies can then produce an anomalous cooling in the western tropical Indian Ocean through wind-evaporation-SST feedback (Tao et al. 2014).

\section{Summary}

In this study, we identify salient differences in eastern China summer rainfall between the mixed type of extreme El Niño in 2015/16 and the pure EP type of extreme El Niño events in 1982/83 and 1997/98. While the 2015/16 event produced similar impacts on MLRYR as the other two events, it produced remarkably increased rainfall over northern China that was opposite to the impacts produced by the other two extreme events and expected by the EP El Niño. We also find the 2015/ 16 event to be accompanied by a southeastern Indian Ocean warming and a western tropical Indian Ocean cooling, which are different from the typical Indian Ocean basin warming observed in the 1982/83 and 1997/ 98 events and expected by the EP El Niño.

We use statistical analyses and climate model experiments to identify the physical processes that enable the Indian Ocean SST anomalies to impact MLRYR and North China rainfall. As illustrated in Fig. 14, the southeastern Indian Ocean warming works together with the EP component of the 2015/16 extreme El Niño to maintain the anomalous anticyclone over the western North Pacific and southeastern China during the decaying summer of the event. The anomalous anticyclone then transports water vapor into MLRYR to increase 


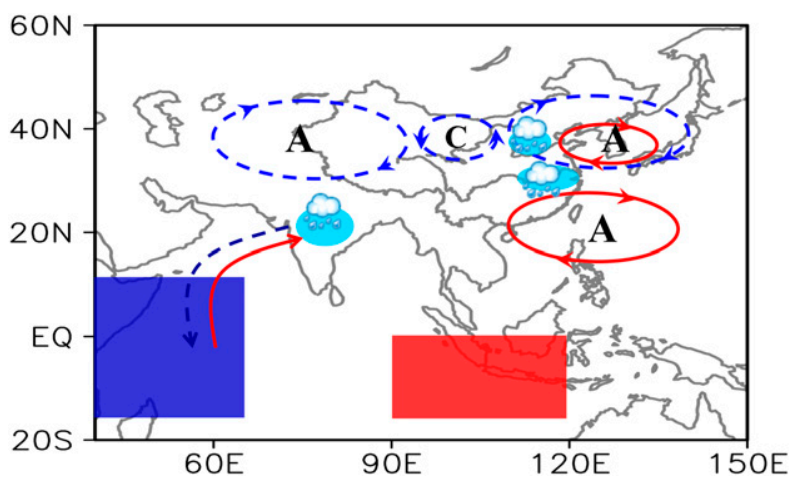

FIG. 14. Schematic diagram summarizing the different influences of southeastern Indian Ocean and western tropical Indian Ocean SST anomalies on eastern China rainfall during the decaying summer of 2015/16 extreme El Niño. The red and blue rectangles indicate the southeastern Indian Ocean warming and western tropical Indian Ocean cooling, respectively. The lower-level and upper-level circulation anomalies are represented by red solid and blue dashed lines, respectively. Letters " $A$ " and " $C$ " denote anticyclone and cyclone, respectively.

rainfall there. As for the western tropical Indian Ocean cooling, it is independent from the EP El Niño. The cooling first enhances the summer monsoon to increase rainfall over central-northern India, which then excites a midlatitude Asian wave train to place an anomalous anticyclone over northeast Asia. The barotropic anticyclone then produces anomalous ascent over northern China and transports water vapor from East China Sea into northern China to increase rainfall there. The unique rainfall anomalies produced by the 2015/16 extreme El Niño prompt the need to study how the conventional views of El Niño impacts on East Asian climate should be revised when the El Niño properties change in the twentyfirst century.

Acknowledgments. This work was jointly supported by the Strategic Priority Research Program of Chinese Academy of Sciences (XDA20060502); the National Natural Science Foundation of China (41925024); Key Special Project for Introduced Talents Team of Southern Marine Science and Engineering Guangdong Laboratory (Guangzhou) (GML2019ZD0306); Innovation Academy of South China Sea Ecology and Environmental Engineering, Chinese Academy of Sciences (ISEE2018PY06); and the Independent Research Project Program of State Key Laboratory of Tropical Oceanography (LTOZZ1802). Author Jiepeng Chen was supported by the National Natural Science Foundation of China (41506004); the Guangdong Natural Science Foundation (2016A030310113); and the open fund of State Key Laboratory of Satellite
Ocean Environment Dynamics, Second Institute of Oceanography (QNHX1801). Author Jin-Yi Yu was supported by National Science Foundation of the United States under Grants AGS-1505145 and AGS1833075. The numerical simulation is supported by the High Performance Computing Division and HPC managers of Wei Zhou and Dandan Sui in the South China Sea Institute of Oceanology.

\section{REFERENCES}

Adler, R. F., and Coauthors, 2003: The Version-2 Global Precipitation Climatology Project (GPCP) monthly precipitation analysis (1979-present). J. Hydrometeor., 4, 11471167, https://doi.org/10.1175/1525-7541(2003)004<1147: TVGPCP $>2.0 . \mathrm{CO} ; 2$.

Ashok, K., S. K. Behera, S. A. Rao, H. Weng, and T. Yamagata, 2007: El Niño Modoki and its possible teleconnection. J. Geophys. Res., 112, C11007, https://doi.org/10.1029/2006JC003798.

Chen, J. P., Z. P. Wen, R. G. Wu, X. Wang, C. He, and Z. S. Chen, 2017: An interdecadal change in the intensity of interannual variability in summer rainfall over southern China around early 1990s. Climate Dyn., 48, 191-207, https://doi.org/10.1007/ s00382-016-3069-8.

, X. Wang, W. Zhou, C. Z. Wang, Q. Xie, G. Li, and S. Chen, 2018: Unusual rainfall in southern China in decaying August during extreme El Niño 2015/16: Role of the western Indian Ocean and north tropical Atlantic SST. J. Climate, 31, 70197034, https://doi.org/10.1175/JCLI-D-17-0827.1.

Chen, M. Y., J.-Y. Yu, X. Wang, and W. P. Jiang, 2019: The changing impact mechanisms of a diverse El Niño on the western Pacific subtropical high. Geophys. Res. Lett., 46, 953 962, https://doi.org/10.1029/2018GL081131.

Chen, Z. S., Y. Du, Z. P. Wen, R. G. Wu, and C. Z. Wang, 2018: Indo-Pacific climate during the decaying phase of the 2015/16 El Niño: Role of southeast tropical Indian Ocean warming. Climate Dyn., 50, 4707-4719, https://doi.org/10.1007/s00382017-3899-z.

Ding, Q. H., and B. Wang, 2005: Circumglobal teleconnection in the Northern Hemisphere summer. J. Climate, 18, 3483-3505, https://doi.org/10.1175/JCLI3473.1.

Feng, J., W. Chen, C. Y. Tam, and W. Zhou, 2011: Different impacts of El Niño and El Niño Modoki on China rainfall in the decaying phases. Int. J. Climatol., 31, 2091-2101, https:// doi.org/10.1002/joc.2217.

Freund, M. B., B. J. Henley, D. J. Karoly, H. V. McGregor, N. J. Abram, and D. Dommenget, 2019: Higher frequency of central Pacific El Niño events in recent decades relative to past centuries. Nat. Geosci., 12, 450-455, https://doi.org/10.1038/ s41561-019-0353-3.

Gao, Y., H. J. Wang, and D. Chen, 2018: Precipitation anomalies in the Pan-Asian monsoon region during El Niño decaying summer 2016. Int. J. Climatol., 38, 3618-3632, https://doi.org/ $10.1002 /$ joc.5522.

Guo, Q. Y., and J. Q. Wang, 1988: A comparison of the summer precipitation in India with that in China (in Chinese). J. Trop. Meteor., 4, 53-60.

Han, T. T., H. J. Wang, and J. Q. Sun, 2017: Strengthened relationship between eastern ENSO and summer precipitation over northeastern China. J. Climate, 30, 4497-4512, https:// doi.org/10.1175/JCLI-D-16-0551.1. 
— S. P. He, H. J. Wang, and X. Hao, 2018: Enhanced influence of early-spring tropical Indian Ocean SST on the following early-summer precipitation over northeast China. Climate Dyn., 51, 4065-4076, https://doi.org/10.1007/s00382-017-3669-y.

He, Z. Q., and R. G. Wu, 2013: Coupled seasonal variability in the South China Sea. J. Oceanogr., 69, 57-69, https://doi.org/ 10.1007/s10872-012-0157-1.

Huang, R., and Y. Wu, 1989: The influence of ENSO on the summer climate change in China and its mechanism. Adv. Atmos. Sci., 6, 21-32, https://doi.org/10.1007/BF02656915.

Kao, H.-Y., and J.-Y. Yu, 2009: Contrasting eastern Pacific and central Pacific types of ENSO. J. Climate, 22, 615-632, https:// doi.org/10.1175/2008JCLI2309.1.

Kobayashi, S., and Coauthors, 2015: The JRA-55 reanalysis: General specifications and basic characteristics. J. Meteor. Soc. Japan, 93, 5-48, https://doi.org/10.2151/jmsj.2015-001.

Kripalani, R. H., and A. Kulkarni, 2001: Monsoon rainfall variations and teleconnections over South and East Asia. Int. J. Climatol., 21, 603-616, https://doi.org/10.1002/joc.625.

Krishnan, R., and M. Sugi, 2001: Baiu rainfall variability and associated monsoon teleconnection. J. Meteor. Soc. Japan, 79, 851-860, https://doi.org/10.2151/jmsj.79.851.

Kug, J.-S., F.-F. Jin, and S.-I. An, 2009: Two types of El Niño events: Cold tongue El Niño and warm pool El Niño. J. Climate, 22, 1499-1515, https://doi.org/10.1175/2008JCLI2624.1.

Lau, K. M., and H. Y. Weng, 2001: Coherent modes of global SST and Summer rainfall over China: An assessment of the regional impacts of the 1997-98 El Niño. J. Climate, 14, 12941308, https://doi.org/10.1175/1520-0442(2001)014<1294: CMOGSA $>2.0 . \mathrm{CO} ; 2$.

Lee, T., and M. J. McPhaden, 2010: Increasing intensity of El Niño in the central-equatorial Pacific. Geophys. Res. Lett., 37, L14603, https://doi.org/10.1029/2010GL044007.

L'Heureux, M., and Coauthors, 2017: Observing and predicting the 2015/16 El Niño. Bull. Amer. Meteor. Soc., 98, 1363-1382, https://doi.org/10.1175/BAMS-D-16-0009.1.

Li, C. F., W. Chen, X. W. Hong, and R. Y. Lu, 2017: Why was the strengthening of rainfall in summer over the Yangtze River valley in 2016 less pronounced than that in 1998 under similar preceding El Niño events?-Role of midlatitude circulation in August. Adv. Atmos. Sci., 34, 1290-1300, https://doi.org/ 10.1007/s00376-017-7003-8.

Li, S. L., J. Lu, G. Huang, and K. M. Hu, 2008: Tropical Indian Ocean basin warming and East Asian summer monsoon: A multiple AGCM study. J. Climate, 21, 6080-6088, https:// doi.org/10.1175/2008JCLI2433.1.

Lindzen, R. S., and N. Nigam, 1987: On the role of sea surface temperature gradients in forcing low-level winds and convergence in the tropics. J. Atmos. Sci., 44, 2418-2436, https://doi.org/10.1175/1520-0469(1987)044<2418:OTROSS> 2.0.CO;2.

Liu, B. Q., C. W. Zhu, J. Z. Su, L. J. Hua, and Y. H. Duan, 2018: Why was the western Pacific subtropical anticyclone weaker in late summer after the 2015/2016 super El Niño? Int. J. Climatol., 38, 55-65, https://doi.org/10.1002/joc.5160.

Neal, R. B., and Coauthors, 2012: Description of the NCAR Community Atmosphere Model (CAM 5.0). NCAR Tech. Note NCAR/TN-4861STR, 274 pp., www.cesm.ucar.edu/ models/cesm1.0/cam/docs/description/cam5_desc.pdf.

NOAA/OAR/ESRL, 2004: NCEP Global Ocean Data Assimilation System (GODAS). NOAA/OAR/ESRL Physical Sciences Division (PSD), accessed 6 February 2018, https://www. esrl.noaa.gov/psd/data/gridded/data.godas.html\#detail.
Paek, H., J.-Y. Yu, and C. Qian, 2017: Why were the 2015/2016 and 1997/1998 extreme El Niños different? Geophys. Res. Lett., 44, 1848-1856, https://doi.org/10.1002/2016GL071515.

,,-- F. Zheng, and M. M. Lu, 2019: Impacts of ENSO diversity on the western Pacific and North Pacific subtropical highs during boreal summer. Climate Dyn., 52, 7153-7172, https://doi.org/10.1007/s00382-016-3288-z.

Praveen Kumar, B., J. Vialard, M. Lengaigne, V. S. N. Murty, and M. J. McPhaden, 2012: TropFlux: Air-sea fluxes for the global tropical oceans-Description and evaluation. Climate Dyn., 38, 1521-1543, https://doi.org/10.1007/s00382-011-1115-0.

Rayner, N. A., D. E. Parker, E. B. Horton, C. K. Folland, L. V. Alexander, D. P. Rowell, E. C. Kent, and A. Kaplan, 2003: A global analysis of sea surface temperature, sea ice, and night marine air temperature since the late nineteenth century. J. Geophys. Res., 108, 4407, https://doi.org/10.1029/ 2002JD002670.

Ren, H. L., and F. F. Jin, 2011: Niño indices for two types of ENSO. Geophys. Res. Lett., 38, L04704, https://doi.org/ 10.1029/2010GL046031.

Ren, R., S. Sun, Y. Yang, and Q. Li, 2016: Summer SST anomalies in the Indian Ocean and the seasonal timing of ENSO decay phase. Climate Dyn., 47, 1827-1844, https://doi.org/10.1007/ s00382-015-2935-0.

Rodwell, M. J., and B. J. Hoskins, 1996: Monsoons and the dynamics of deserts. Quart. J. Roy. Meteor. Soc., 122, 1385-1404, https://doi.org/10.1002/qj.49712253408.

Saji, N. H., B. N. Goswami, P. N. Vinayachandran, and T. Yamagata, 1999: A dipole mode in the tropical Indian Ocean. Nature, 401, 360-363, https://doi.org/10.1038/43854.

Tao, W. C., G. Huang, K. M. Hu, X. Qu, G. H. Wen, and Y. F. Gong, 2014: Different influences of two types of El Niños on the Indian Ocean SST variations. Theor. Appl. Climatol., 117, 475-484, https://doi.org/10.1007/s00704-013-1022-x.

Wang, B., R. G. Wu, and X. H. Fu, 2000: Pacific-East Asian teleconnection: How does ENSO affect East Asian climate? J. Climate, 13, 1517-1536, https://doi.org/10.1175/15200442(2000)013<1517:PEATHD > 2.0.CO;2.

—, J. Liu, J. Yang, T. J. Zhou, and Z. W. Wu, 2009: Distinct principal modes of early and late summer rainfall anomalies in East Asia. J. Climate, 22, 3864-3875, https://doi.org/10.1175/ 2009JCLI2850.1.

Wang, C., and X. Wang, 2013: Classifying El Niño Modoki I and II by different impacts on rainfall in southern China and typhoon tracks. J. Climate, 26, 1322-1338, https://doi.org/10.1175/JCLID-12-00107.1.

Wei, W., R. H. Zhang, M. Wen, X. Y. Rong, and T. Li, 2014: Impact of Indian summer monsoon on the South Asian high and its influence on summer rainfall over China. Climate Dyn., 43, 1257-1269, https://doi.org/10.1007/s00382-013-1938-y.

$-, \ldots,-$, and S. Yang, 2017: Relationship between the Asian westerly jet stream and summer rainfall over central Asia and North China: Roles of the Indian monsoon and the South Asian high. J. Climate, 30, 537-552, https://doi.org/ 10.1175/JCLI-D-15-0814.1.

Weng, H., K. Ashok, S. K. Behera, and S. A. Rao, 2007: Impacts of recent El Niño Modoki on dry/wet conditions in the Pacific Rim during boreal summer. Climate Dyn., 29, 113-129, https:// doi.org/10.1007/s00382-007-0234-0.

, S. K. Behera, and T. Yamagata, 2009: Anomalous winter climate conditions in the Pacific Rim during recent El Niño Modoki and El Niño events. Climate Dyn., 32, 663-674, https:// doi.org/10.1007/s00382-008-0394-6. 
Wu, B., T. J. Zhou, and T. Li, 2009: Seasonally evolving dominant interannual variability modes of East Asian climate. J. Climate, 22, 2992-3005, https://doi.org/10.1175/2008JCLI2710.1.

Wu, R. G., 2002: A mid-latitude Asian circulation anomaly pattern in boreal summer and its connection with the Indian and East Asian summer monsoons. Int. J. Climatol., 22, 1879-1895, https://doi.org/10.1002/joc.845.

_ 2017: Relationship between Indian and East Asian summer rainfall variations. Adv. Atmos. Sci., 34, 4-15, https://doi.org/ 10.1007/s00376-016-6216-6.

— , and B. Wang, 2002: A contrast of the East Asian summer monsoon-ENSO relationship between 1962-77 and 1978-93. J. Climate, 15, 3266-3279, https://doi.org/10.1175/1520-0442(2002) 015<3266:ACOTEA > 2.0.CO;2.

— Z. Z. Hu, and B. P. Kirtman, 2003: Evolution of ENSOrelated rainfall anomalies in East Asia. J. Climate, 16, 3742 3758, https://doi.org/10.1175/1520-0442(2003)016<3742:EOERAI > 2.0.CO;2.

—, S. Yang, Z. P. Wen, G. Huang, and K. M. Hu, 2012: Interdecadal change in the relationship of southern China summer rainfall with tropical Indo-Pacific SST. Theor. Appl. Climatol., 108, 119-133, https://doi.org/10.1007/s00704-011-0519-4.

Xie, P. P., and P. A. Arkin, 1997: Global precipitation: A 17year monthly analysis based on gauge observations, satellite estimates, and numerical model outputs. Bull. Amer. Meteor. Soc., 78, 2539-2558, https://doi.org/10.1175/15200477(1997)078<2539:GPAYMA > 2.0.CO;2.

Xie, S. P., K. M. Hu, J. Hafner, H. Tokinaga, Y. Du, G. Huang, and T. Sampe, 2009: Indian Ocean capacitor effect on Indo-western Pacific climate during the summer following El Niño. J. Climate, 22, 730-747, https://doi.org/10.1175/ 2008JCLI2544.1.

Xue, Y., and A. Kumar, 2017: Evolution of the 2015/16 El Niño and historical perspective since 1979. Sci. China Earth Sci., 60, 1572-1588, https://doi.org/10.1007/s11430-016-0106-9.

Yang, J. L., Q. Y. Liu, S. P. Xie, Z. Y. Liu, and L. X. Wu, 2007: Impact of the Indian Ocean SST basin mode on the Asian summer monsoon. Geophys. Res. Lett., 34, L02708, https:// doi.org/10.1029/2006GL028571.

Yeh, S. W., J. S. Kug, B. Dewitte, M. H. Kwon, B. P. Kirtman, and F. F. Jin, 2009: El Niño in a changing climate. Nature, 461, 511514, https://doi.org/10.1038/nature08316.
Yu, J.-Y., and S. T. Kim, 2010: Identification of central-Pacific and eastern-Pacific types of ENSO in CMIP3 models. Geophys. Res. Lett., 37, L15705, https://doi.org/10.1029/ 2010GL044082.

_, and - 2011: Relationships between extratropical sea level pressure variations and the central Pacific and eastern Pacific types of ENSO. J. Climate, 24, 708-720, https://doi.org/ 10.1175/2010JCLI3688.1.

- , H. Y. Kao, and T. Lee, 2010: Subtropics-related interannual sea surface temperature variability in the equatorial central Pacific. J. Climate, 23, 2869-2884, https://doi.org/10.1175/ 2010JCLI3171.1.

—- M. M. Lu, and S. T. Kim, 2012: A change in the relationship between tropical central Pacific SST variability and the extratropical atmosphere around 1990. Environ. Res. Lett., 7, 034025, https://doi.org/10.1088/1748-9326/7/3/ 034025.

——, P. K. Kao, H. Paek, H. H. Hsu, C. W. Hung, M. M. Lu, and S. I. An, 2015: Linking emergence of the central Pacific El Niño to the Atlantic multidecadal oscillation. J. Climate, 28, 651-662, https://doi.org/10.1175/JCLI-D14-00347.1.

Yuan, Y., and S. Yang, 2012: Impacts of different types of El Niño on the East Asian climate: Focus on ENSO cycles. J. Climate, 25, 7702-7722, https://doi.org/10.1175/JCLI-D11-00576.1.

_ — , and Z. Zhang, 2012: Different evolutions of the Philippine Sea anticyclone between the eastern and central Pacific El Niño: Possible effects of Indian Ocean SST. J. Climate, 25, 7867-7883, https://doi.org/10.1175/JCLI-D-12-00004.1.

- , H. Gao, W. J. Li, Y. J. Liu, L. J. Chen, B. Zhou, and Y. H. Ding, 2017: The 2016 summer floods in China and associated physical mechanisms: A comparison with 1998. J. Meteor. Res., 31, 261-277, https://doi.org/10.1007/s13351-017-6192-5.

Zhang, R. H., A. Sumi, and M. Kimoto, 1999: A diagnostic study of the impact of El Niño on the precipitation in China. $A d v$. Atmos. Sci., 16, 229-241, https://doi.org/10.1007/BF02973084. , Q. Y. Min, and J. Z. Su, 2017: Impact of El Niño on atmospheric circulations over East Asia and rainfall in China: Role of the anomalous western North Pacific anticyclone. Sci. China Earth Sci., 60, 1124-1132, https://doi.org/10.1007/ s11430-016-9026-x. 